\title{
Laser ablation aerosol particle time-of-flight mass spectrometer (LAAPTOF): performance, reference spectra and classification of atmospheric samples
}

\author{
Xiaoli Shen ${ }^{1,2}$, Ramakrishna Ramisetty ${ }^{1}$, Claudia Mohr ${ }^{1, a}$, Wei Huang ${ }^{1,2}$, Thomas Leisner $^{1}$, and Harald Saathoff ${ }^{1}$ \\ ${ }^{1}$ Institute of Meteorology and Climate Research (IMK-AAF), Karlsruhe Institute of Technology (KIT), \\ Hermann-von-Helmholtz-Platz 1, 76344 Eggenstein-Leopoldshafen, Germany \\ ${ }^{2}$ Institute of Geography and Geoecology (IfGG), Karlsruhe Institute of Technology (KIT), Kaiserstr. 12 , \\ 76131 Karlsruhe, Germany \\ ${ }^{a}$ now at: Department of Environmental Science and Analytical Chemistry, Stockholm University, \\ Stockholm, 11418, Sweden
}

Correspondence: Harald Saathoff (harald.saathoff@ kit.edu)

Received: 18 September 2017 - Discussion started: 8 November 2017

Revised: 2 February 2018 - Accepted: 28 March 2018 - Published: 24 April 2018

\begin{abstract}
The laser ablation aerosol particle time-of-flight mass spectrometer (LAAPTOF, AeroMegt $\mathrm{GmbH}$ ) is able to identify the chemical composition and mixing state of individual aerosol particles, and thus is a tool for elucidating their impacts on human health, visibility, ecosystem, and climate. The overall detection efficiency (ODE) of the instrument we use was determined to range from $\sim(0.01 \pm 0.01)$ to $\sim(4.23 \pm 2.36) \%$ for polystyrene latex (PSL) in the size range of 200 to $2000 \mathrm{~nm}, \sim(0.44 \pm 0.19)$ to $\sim(6.57 \pm 2.38) \%$ for ammonium nitrate $\left(\mathrm{NH}_{4} \mathrm{NO}_{3}\right)$, and $\sim(0.14 \pm 0.02)$ to $\sim(1.46 \pm 0.08) \%$ for sodium chloride $(\mathrm{NaCl})$ particles in the size range of 300 to $1000 \mathrm{~nm}$. Reference mass spectra of 32 different particle types relevant for atmospheric aerosol (e.g. pure compounds $\mathrm{NH}_{4} \mathrm{NO}_{3}$, $\mathrm{K}_{2} \mathrm{SO}_{4}, \mathrm{NaCl}$, oxalic acid, pinic acid, and pinonic acid; internal mixtures of e.g. salts, secondary organic aerosol, and metallic core-organic shell particles; more complex particles such as soot and dust particles) were determined. Our results show that internally mixed aerosol particles can result in spectra with new clusters of ions, rather than simply a combination of the spectra from the single components. An exemplary 1-day ambient data set was analysed by both classical fuzzy clustering and a reference-spectra-based classification method. Resulting identified particle types were generally well correlated. We show how a combination of both methods can greatly improve the interpretation of single-particle data in field measurements.
\end{abstract}

\section{Introduction}

Atmospheric aerosol particles impact visibility, interact with trace gases, can act as cloud condensation and ice nuclei, and influence the Earth's radiation budget (Seinfeld and Pandis, 2006). Especially the continuously evolving chemical composition of aerosol particles is of scientific interest, as it influences all aerosol effects (Burkholder et al., 2017; Pöschl, 2005). However, large knowledge gaps still exist related to the chemical composition of the organic and inorganic components and their mutual interaction (Jimenez et al., 2009; Murphy et al., 2006; Schill and Tolbert, 2013; Zhang et al., 2007).

Aerosol particles can contain various components, ranging from volatile to refractory species (Pratt and Prather, 2012). The global aerosol mass burden was estimated to consist of $73.6 \%$ dust, $16.7 \%$ sea salt, $2.8 \%$ biogenic secondary organic aerosols (SOA), $2.3 \%$ primary organic aerosols (POA), $1.3 \%$ sulfate, $1.3 \%$ ammonium, $1.2 \%$ nitrate, $0.4 \%$ black carbon (soot), $0.2 \%$ anthropogenic SOA, and $0.2 \%$ methane sulfonic acid (Tsigaridis et al., 2006). During the ambient aerosols' lifetime, ranging from hours to a few weeks (Pöschl, 2005), the complexity of their chemical composition usually increases by coagulation, cloud processing, and chemical reactions (Seinfeld and Pandis, 2006; Usher et al., 2003). This modifies the particles' mixing state, with both internal (individual particles consisting of mixed 
compounds, e.g. coating structures) and external mixtures, e.g. mixture of particles consisting of different compounds (Li et al., 2016). The aforementioned findings underscore the importance of measuring aerosol chemical composition and its changes on short timescales and on a single-particle basis, which can be realized by online mass spectrometry.

Online mass spectrometry includes bulk and singleparticle measurements (Pratt and Prather, 2012). Singleparticle mass spectrometry, which can be dated back to the 1970s, aims at in situ and real-time identification of the chemical composition of individual aerosol particles, hereby elucidating a particle's external and internal mixing properties (Noble and Prather, 2000). Online single-particle mass spectrometers (SPMSs) commonly use pulsed lasers for particle desorption and ionization (LDI), with the advantage of ionizing nearly all atmospheric particle components, including both non-refractory and refractory materials (Kulkarni et al., 2011). To the best of our knowledge, so far there is no quantitative analysis of particle composition by SPMS, since the ablation/ionization laser cannot interact with the entire particle and the generated ion fragments/clusters are susceptible to matrix effects (Ramisetty et al., 2017). In addition, ionization mechanisms are not fully understood (Murphy, 2007). SPMSs have identified many different ambient particle types in different regions of the atmosphere, such as elemental carbon and organic carbon (ECOC), organic sulfate, aged sea salt, biological, soil dust, and different metal dominated types (Dall'Osto et al., 2016; Moffet et al., 2008; Murphy et al., 2006; Schmidt et al., 2017). These measurements all confirmed the complexity of individual particles' mixing state and demonstrated the usefulness of single-particle mass spectra for apportionment of individual particle sources, including e.g. fossil fuel and biomass burning combustion, cooking, marine, and shipping sources (Arndt et al., 2017; Schmidt et al., 2017).

Currently, there are only two commercially available SPMSs, i.e. the single-particle aerosol mass spectrometer (SPAMS, Hexin Analytical Instrument Co., Ltd., China; Li et al., 2011; Lin et al., 2017) and the laser ablation aerosol particle time-of-flight mass spectrometer (LAAPTOF, AeroMegt $\mathrm{GmbH}$, Germany). LAAPTOF uses two laser diodes (405 nm wavelength, $\sim 40 \mathrm{~mW}, \sim 50 \mu \mathrm{m}$ beam spot diameter; Marsden et al., 2016; Zawadowicz et al., 2017) for optical counting and size recording by light scattering, and one excimer laser (ArF, $193 \mathrm{~nm}, \sim 4 \mathrm{~mJ}$ ) for one-step ablation/ionization. The overall detection efficiency (ODE) of this instrument, defined as the number of single-particle mass spectra obtained from the total number of aerosol particles in the sampled air, was determined to range from $\sim 0.15$ to $\sim 2.2 \%$ for polystyrene latex (PSL) particles with geometric diameters $\left(d_{\mathrm{p}}\right)$ between $350 \mathrm{~nm}$ and $800 \mathrm{~nm}$ (Gemayel et al., 2016; Marsden et al., 2016). The instrument used by Gemayel et al. (2016) exhibited a maximum ODE of $\sim 2.2 \%$ for PSL particle diameters of $450 \mathrm{~nm}$, while $\sim 1 \%$ at $600 \mathrm{~nm}$ was the peak ODE reported by Marsden et al. (2016) be- fore the instrument modification. Neither the response of the LAAPTOF to spherical PSL particles smaller than $350 \mathrm{~nm}$ and bigger than $800 \mathrm{~nm}$ nor the response to other particle types with different shapes has been investigated systematically. The scattering efficiency (SE), defined as the number fraction of particles detected by light scattering compared to the number of particles in the sampled air in front of the aerodynamic inlet lens (ADL) of the instrument (refer to Fig. 1), is determined by the laser diodes, the detection optics, and the photomultiplier tubes (PMT), and it has a strong influence on the ODE of the instrument. Therefore, several groups have tried to improve this part of the instrument. Marsden et al. (2016) modified the detection stage geometry by replacing the detection laser with a fibre-coupled $532 \mathrm{~nm}, 1 \mathrm{~W} \mathrm{Nd:YAG}$ solid-state laser system with a collimated laser beam, accomplishing an order-of-magnitude improvement in light detection sensitivity to PSL particles with $500-800 \mathrm{~nm}$ diameter. Zawadowicz et al. (2017) modified the optical path of the laser diodes with a better laser beam of $<1 \mathrm{mrad}$ full-angle divergence and $100 \mu \mathrm{m}$ detection beam spot size, and applied light guides to enhance the scattered-light collection. This resulted in improvement of 2-3 orders of magnitude in optical counting efficiency of incident PSL particles with 500$2000 \mathrm{~nm}$ vacuum aerodynamic diameter $\left(d_{\mathrm{va}}\right)$. There are only very few studies so far that discuss mass spectral patterns of different particle types measured by LAAPTOF. Gemayel et al. (2016) presented spectra from ambient particles collected in the city centre of Marseille, France; spectra (positive only) from pure soot and SOA-coated soot particles were shown by Ahern et al. (2016); spectra from potassium rich feldspar, soot, Argentinian soil dust, and Snomax (commercial ice nuclei) were shown by Zawadowicz et al. (2017); PSL and potassium rich feldspar spectra were measured by Marsden et al. (2018); and radiolytically formed particles spectra were measured by Wonaschuetz et al. (2017). Reitz et al. (2016) presented peak assignments for pure ammonium nitrate and sulfate particles, as well as for ambient particles measured at a suburban site of Düsseldorf, Germany, but did not show any spectra. Marker ions generated from SPMS are likely instrument specific, as pointed out by Schmidt et al. (2017). Therefore, there is a need for publicly available spectral information of this relatively new instrument.

There exists several techniques to group the large number of individual particle types and spectra resulting from SMPS measurements - such as $k$-means, $c$-means, and hierarchical clustering algorithms; neural-network-based methods such as ART2-A; and the most recent algorithm of ordering points to identify the clustering structure (OPTICS) - to help analyse the data (Hinz et al., 1999; Murphy et al., 2003; Reitz et al., 2016; Zelenyuk et al., 2006b; Zhao et al., 2008). There also exist target (reference spectra/predefined clusters)-oriented methods (Hinz et al., 1999; Gleanta GmbH; LAAPTOF AnalysisPro, AeroMegt GmbH).

In this paper we have characterized our LAAPTOF instrument with respect to its ODE for PSL, $\mathrm{NH}_{4} \mathrm{NO}_{3}$, and 


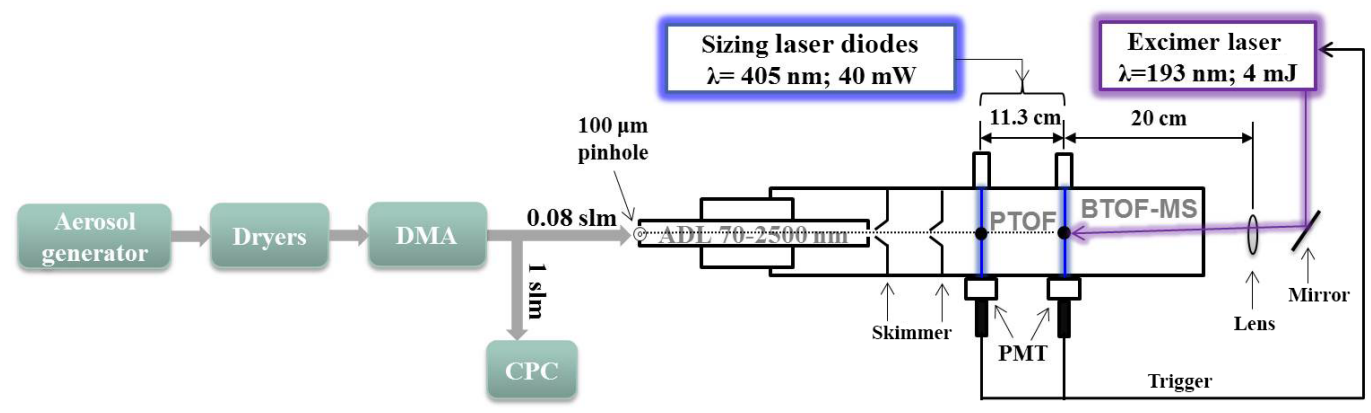

Figure 1. Schematic of the LAAPTOF instrument and the experimental setup for measuring standard samples (method A), e.g. PSL, $\mathrm{NH}_{4} \mathrm{NO}_{3}$, and $\mathrm{K}_{2} \mathrm{SO}_{4}$ particles, which were generated from a nebulizer, passed through two dryers, were size-selected by a differential mobility analyser (DMA), and were then measured by LAAPTOF.

sodium chloride $(\mathrm{NaCl})$ particles for a wide size range $\left(d_{\mathrm{m}}\right.$ : 200-2000 nm PSL; 300-1000 $\mathrm{nm} \mathrm{NH}_{4} \mathrm{NO}_{3}$ and $\mathrm{NaCl}$ ). We present laboratory-based reference spectra for aerosol particles containing atmospherically relevant components, which were grouped into three categories: (1) particles consisting of pure compounds, e.g. $\mathrm{NH}_{4} \mathrm{NO}_{3}, \mathrm{~K}_{2} \mathrm{SO}_{4}$, and organic acids; (2) particles consisting of well-defined mixtures of pure salts and mixtures of organic compounds, e.g. $\alpha$-pinene SOA, and PSL internally mixed with $\mathrm{K}_{2} \mathrm{SO}_{4}$, as well as other coreshell type of particles; and (3) particles consisting of complex mixtures, e.g. soot and dust particles. These reference spectra may also provide other users comprehensive references for comparison purposes and thus help better interpret ambient data. An example of field data analysis based on reference spectra as well as fuzzy $c$-means clustering will be given in Sect. 3.3.

\section{Methods}

\subsection{The LAAPTOF instrument}

The LAAPTOF has been described in several recent publications (Ahern et al., 2016; Gemayel et al., 2016; Marsden et al., 2016, 2018; Reitz et al., 2016; Wonaschuetz et al., 2017; Zawadowicz et al., 2017). Therefore, here we only briefly review the general operation steps that yield size and composition information of individual aerosol particles. The LAAPTOF instrument used in this study was delivered in April 2015 and may differ in a few technical aspects from earlier or later versions. A schematic of the main LAAPTOF components is given in Fig. 1. Particles with a vacuum aerodynamic diameter $\left(d_{\mathrm{va}}\right)$ between $\sim 70 \mathrm{~nm}$ and $2.5 \mu \mathrm{m}$ are sampled with a sampling flow rate of $~ 80$ standard cubic centimetres per minute (SCCM); focused and accelerated by an ADL (LPL-2.5, AeroMegt $\mathrm{GmbH}$ ) with close to $100 \%$ transmission efficiency for particles with $d_{\mathrm{va}} 100 \mathrm{~nm}$ to $2 \mu \mathrm{m}$ (http://www.aeromegt.com/ \#products?LPL-2.5_details, last access: 16 April 2018); and then pass through the particle time-of-flight (PTOF) chamber in which the individual particle can be detected by two sizing laser beams ( $405 \mathrm{~nm}$ continuous wave, $40 \mathrm{~mW}$ ) separated by $11.3 \mathrm{~cm}$. Based on the particle time of flight between the two laser beams, its $d_{\mathrm{va}}$ can be determined and recorded. After detection by the second sizing laser, a nanosecond excimer laser pulse (wavelength: $193 \mathrm{~nm}$; pulse duration: 4 to $8 \mathrm{~ns}$; maximum pulse energy: $\sim 8 \mathrm{~mJ}$; beam diameter: $\sim 300 \mu \mathrm{m}$ when it hits the particle (Ramisetty et al., 2017); power density: $\sim 10^{9} \mathrm{~W} \mathrm{~cm}^{-2}$; ATLEX-S, ATL Lasertechnik GmbH) can be triggered to desorb and ionize particle compounds. A laser pulse energy of $4 \mathrm{~mJ}$ was used for all the measurements in this study. More details about the ionization region geometry are given by Ramisetty et al. (2017). The resulting ions are analysed by a bipolar time-of-flight mass spectrometer (BTOF-MS; TOFWERK AG; mass resolution of $m / \Delta m \sim 600$ to 800 at $184 \mathrm{Th}$, mass range $m / q=1$ up to $\sim 2000 \mathrm{Th}$ ). The cations and anions are detected by corresponding microchannel plate arrays (MCPs), producing a pair of positive and negative spectra for each single particle.

\subsection{Aerosol particle generation and experimental setup in the laboratory}

The laboratory-based aerosol particles measured in this study (summarized in Table 1) were generated in four different ways (A, B1, B2, and S).

Method A: samples for pure particles and homogeneous and heterogeneous mixtures were dissolved/suspended in purified water and nebulized (ATM 221, Topas GmbH) with dry synthetic air, passed through two diffusion dryers (cylinder filled with Silica gel, Topas $\mathrm{GmbH}$ ), and then size-selected by a differential mobility analyser (DMA 3080, TSI GmbH) before being sampled by LAAPTOF.

Method B1: particles were sampled from the $84.5 \mathrm{~m}^{3} \mathrm{sim}$ ulation chamber AIDA (Aerosol Interactions and Dynamics in the Atmosphere) of KIT (Saathoff et al., 2003). SOA particles were formed in the $3.7 \mathrm{~m}^{3}$ stainless-steel Aerosol Preparation and Characterization (APC) chamber via ozonolysis ( $\sim 6$ ppm ozone) of $\alpha$-pinene $(\sim 2.2 \mathrm{ppm})$ and then transferred into AIDA. Soil dust samples were dispersed by a ro- 
Table 1. Overview of laboratory-generated aerosol particles for reference mass spectra.

\begin{tabular}{|c|c|c|c|c|c|c|}
\hline Aerosol particle types & Size $(\mathrm{nm})$ & Width $^{\mathrm{a}}$ & Morphology & Source & $\begin{array}{l}\text { Generation } \\
\text { method }\end{array}$ & $\begin{array}{l}\text { No. of } \\
\text { spectra }\end{array}$ \\
\hline \multicolumn{7}{|l|}{ 1. Particles consisting of pure compounds } \\
\hline Ammonium nitrate, $\mathrm{NH}_{4} \mathrm{NO}_{3}$ & 1160 & 101 & aspherical & $\geq 99.5 \%$, Fluka & A & 497 \\
\hline Ammonium sulfate ${ }^{\mathrm{b}},\left(\mathrm{NH}_{4}\right)_{2} \mathrm{SO}_{4}$ & 611 & 79 & aspherical & $\geq 99.5 \%$, Merck & A & 537 \\
\hline Potassium sulfate, $\mathrm{K}_{2} \mathrm{SO}_{4}$ & 1465 & 232 & aspherical & $\geq 99 \%$, Merck & A & 300 \\
\hline Sodium chloride, $\mathrm{NaCl}$ & 1202 & 133 & cubic & $\geq 99.5 \%$, Merck & A & 250 \\
\hline Silica, $\mathrm{SiO}_{2}$ (Glass beads) & 2097 & 44 & spherical & Palas GmbH & S & 347 \\
\hline Oxalic acid, $\mathrm{C}_{2} \mathrm{H}_{4} \mathrm{O}_{2}$ & 1081 & 322 & spherical & Merck & A & 736 \\
\hline Pinic acid, $\mathrm{C}_{9} \mathrm{H}_{14} \mathrm{O}_{4}$ & 902 & 94 & spherical & University of Mainz & A & 683 \\
\hline Cis-pinonic acid, $\mathrm{C}_{10} \mathrm{H}_{16} \mathrm{O}_{3}$ & 702 & 88 & spherical & $98 \%$, ACROS ORGANICS & A & 600 \\
\hline Humic acid & 1221 & 126 & spherical & $100 \%$, Alfa Aesar & A & 773 \\
\hline Polystyrene latex (PSL) & 818 & 3 & spherical & Thermo scientific & A & 235 \\
\hline \multicolumn{7}{|l|}{ 2. Particles consisting of well-defined mixtures } \\
\hline $\begin{array}{l}\text { Ammonium nitrate } \& \text { ammonium sulfate } \\
(\text { mass ratio }=1: 1)\end{array}$ & 1102 & 165 & aspherical & $\begin{array}{l}\text { Single-component samples } \\
\text { are from the same source }\end{array}$ & A & 454 \\
\hline $\begin{array}{l}\text { Potassium sulfate } \& \text { sodium chloride } \\
(\text { mass ratio }=1: 1)\end{array}$ & 1375 & 197 & aspherical & $\begin{array}{l}\text { as the corresponding pure } \\
\text { compounds }\end{array}$ & & 259 \\
\hline $\begin{array}{l}\text { Ammonium nitrate } \& \text { potassium sulfate } \\
(\text { mass ratio }=2: 1)\end{array}$ & 854 & 112 & aspherical & & & 576 \\
\hline Hematite & 1091 & 817 & spherical & $\begin{array}{l}\text { Karlsruhe Institute of } \\
\text { Technology (KIT) }\end{array}$ & S & 320 \\
\hline Pure sea salt & 1205 & 218 & cubic & Sigma Aldrich & B1 & 422 \\
\hline$\alpha-$ Pinene secondary organic aerosols (SOA) & 505 & 84 & spherical & $\begin{array}{l}(1 S)-(-)-\alpha \text {-pinene } \\
(99 \%) \text { from Aldrich }\end{array}$ & $\mathrm{B} 1^{\mathrm{c}}$ & 1938 \\
\hline Potassium-sulfate-coated PSL & 805 & 58 & partially coated & Merck \& Thermo scientific & A & 609 \\
\hline Poly(allylamine hydrochloride)-coated gold & $400^{\mathrm{d}}$ & & $\begin{array}{l}300 \mathrm{~nm} \text { core- } \\
50 \mathrm{~nm} \text { shell }\end{array}$ & Nanopartz Inc. & $\begin{array}{l}\text { Nebulized } \\
\text { without sizing }\end{array}$ & 417 \\
\hline \multicolumn{7}{|l|}{ 3. Particles consisting of complex mixtures } \\
\hline Soot 1 with low organic carbon & $386^{\mathrm{e}}$ & 275 & agglomerates & $\begin{array}{l}\text { incomplete combustion of } \\
\text { propane, } \mathrm{C} / \mathrm{O}=0.29\end{array}$ & B2 & 617 \\
\hline Soot 1 with high organic carbon & $120^{\mathrm{e}}$ & 58 & agglomerates & $\begin{array}{l}\text { incomplete combustion of } \\
\text { propane, } \mathrm{C} / \mathrm{O}=0.54\end{array}$ & B2 & 347 \\
\hline Soot 2, diesel particles & $624 \pm 980^{f}$ & & agglomerates & NIST (2975) & $\mathrm{S}$ & 533 \\
\hline Soot 3, lignocellulosic char & 828 & 766 & agglomerates & $\begin{array}{l}\text { lignocellulosic char from } \\
\text { chestnut wood; } \\
\text { University of Zurich, } \\
\text { Switzerland }\end{array}$ & $\mathrm{S}$ & 390 \\
\hline Arizona test dust & 1169 & 874 & aspherical & Powder Technology Inc. & $\mathrm{S}$ & 261 \\
\hline Saharan dust 1 (Morocco) & 890 & 1230 & aspherical & $\begin{array}{l}\text { Konrad Kandler, } \\
\text { TU Darmstadt }\end{array}$ & S & 338 \\
\hline Saharan dust 2 (Cairo) & $1334 \pm 1454^{\mathrm{f}}$ & & aspherical & $\begin{array}{l}\text { Khaled Megahed, } \\
\text { KIT }\end{array}$ & $\mathrm{S}$ & 396 \\
\hline $\begin{array}{l}\text { Arable soil dust SDGe } 01 \\
\text { (Gottesgabe, Germany) }\end{array}$ & 912 & 392 & aspherical & Roger Funk ${ }^{g}$ & $\mathrm{~B} 1^{\mathrm{h}}$ & 583 \\
\hline $\begin{array}{l}\text { Arable soil dust SDPA01 } \\
\text { (Paulinenaue, Germany) }\end{array}$ & 787 & 334 & aspherical & Roger Funk ${ }^{g}$ & $\mathrm{~B} 1^{\mathrm{h}}$ & 385 \\
\hline $\begin{array}{l}\text { Arable soil dust SDAr08 } \\
\text { (Argentina) }\end{array}$ & 910 & 407 & aspherical & Roger Funk ${ }^{g}$ & $\mathrm{~B} 1^{\mathrm{h}}$ & 592 \\
\hline $\begin{array}{l}\text { Arable soil dust SDWY01 } \\
\text { (Wyoming, USA) }\end{array}$ & 864 & 430 & aspherical & Tom Hill ${ }^{\mathrm{i}}$ & $\mathrm{B} 1^{\mathrm{h}}$ & 623 \\
\hline $\begin{array}{l}\text { Agricultural soil dust } \\
\text { (northern Germany) }\end{array}$ & 561 & 249 & aspherical & Roger Funk ${ }^{g}$ & $\mathrm{~B} 1^{\mathrm{h}}$ & 286 \\
\hline Urban dust & 1329 & 1266 & aspherical & NIST(1649a) & $\mathrm{S}$ & 375 \\
\hline Illite_NX & 825 & 260 & sheet & Arginotec & $\mathrm{S}$ & 807 \\
\hline Sea salt with Skeletonema marinoi ${ }^{j}$ & 1212 & 338 & cubic & Matt Salter ${ }^{\mathrm{j}}$ & B1 & 526 \\
\hline 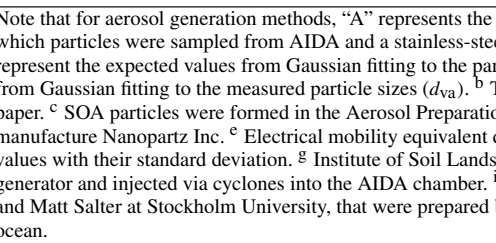 & $\begin{array}{l}\text { thod of using a nebu } \\
\text { ylinder, respectively } \\
\text { le sizes measured by } \\
\text { re is only one weak } \\
\text { and Characterization } \\
\text { meter, } d_{\mathrm{m}} \text {, measured } \\
\text { pe Research, Leibniz } \\
\text { epartment of Atmos } \\
\text { diluting a pure Skele }\end{array}$ & $\begin{array}{l}\text { tre for } A- \\
\text { c Scien } \\
\text { matar }\end{array}$ & $\begin{array}{l}\text { mobility particle si } \\
\text { ricultural Landscap } \\
\text { Colorado State Un }\end{array}$ & 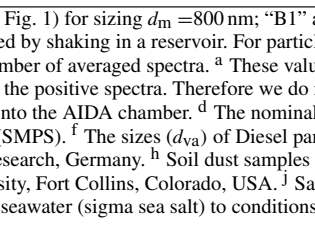 & $\begin{array}{l}\text { d"B2" represent the } \\
\text { size information, } d \\
\text { represent the standi } \\
\text { t give the reference } \\
\text { eometric size given } \\
\text { cles and Saharan dus } \\
\text { ere dispersed by a ro } \\
\text { ples, provided by El } \\
\text { epresentative of a blc }\end{array}$ & $\begin{array}{l}\text { ethods in } \\
\text { values } \\
\text { deviation } \\
\text { ctra in this } \\
\text { the } \\
\text { are average } \\
\text { ing brush } \\
\text { Gorokhove } \\
n \text { in the }\end{array}$ \\
\hline
\end{tabular}


tating brush generator (RBG1000, PALAS) and injected via cyclones into the AIDA chamber. Sea salt particles were generated and injected into AIDA by ultrasonically nebulizing artificial seawater (Sigma Aldrich) and highly concentrated Skeletonema marinoi culture (in artificial seawater), respectively, via a droplet separator and two diffusion dryers (Wagner et al., 2018).

Method B2 was used only for soot particles, which were generated with a propane burner (RSG miniCAST; Jing Ltd.) and injected into and sampled from a stainless-steel cylinder of $0.2 \mathrm{~m}^{3}$ volume.

Method S: silica, hematite, illite NX, Arizona test dust, desert and urban dust, black carbon from chestnut wood (University of Zurich, Switzerland), and diesel soot reference particles from NIST were suspended in their reservoir bottles by shaking them and sampled directly from the headspace (upper part) of these reservoirs through a tube connecting it with the LAAPTOF.

For all the measurements, except measuring the particles generated by method $\mathrm{S}$, a condensation particle counter (CPC 3010, TSI GmbH) was used to record the particle number concentration in parallel with the LAAPTOF inlet. The setup in Fig. 1 was specific for particles generated from method A.

\subsection{Field measurement}

Unusually high particle number concentrations, similar to downtown Karlsruhe (a city in southwest Germany), were observed frequently northeast of Karlsruhe by particle counters on board a tram wagon (www.aero-tram.kit.edu, last access: 16 April 2018) intersecting the city (Hagemann et al., 2014). To study the nature and to identify possible sources of these particles, their number, size, chemical composition, associated trace gases, and meteorological conditions were measured from 15 July to 1 September 2016 at a rural location $\left(49^{\circ} 6^{\prime} 10.54^{\prime \prime} \mathrm{N}, 8^{\circ} 24^{\prime} 26.07^{\prime \prime} \mathrm{E}\right)$, next to the tram line north of the village of Leopoldshafen, Germany. Ambient aerosol particles were sampled through a $\mathrm{PM}_{2.5}$ inlet $(\mathrm{SH}$ 2.5-16, Comde-Derenda $\mathrm{GmbH}$ ) with $1 \mathrm{~m}^{3} \mathrm{~h}^{-1}$, a fraction of which was guided into the LAAPTOF, which was deployed for $\sim 5$ weeks from 26 July to 31 August. LAAPTOF measurements provided information on size and mass spectral patterns for individual particles. In this paper we use data from 1 day as an example of the potential interpretation of LAAPTOF spectral data using reference spectra.

\subsection{Efficiency calculations}

In the literature, two definitions of detection efficiency (DE) of SPMS are used: one is equal to the scattering efficiency (SE) of the detection lasers (Brands et al., 2011; Gaie-Levrel et al., 2012; Su et al., 2004; Zelenyuk and Imre, 2005; Zelenyuk et al., 2009), which is the fraction of particles detected by the scattering optics in the detection region of the instrument; the other one is the product of SE and hit rate (HR) of the ablation/ionization laser (Su et al., 2004; Gemayel et al., 2016; Marsden et al., 2016). The hit rate is the fraction of particles detected actually leading to a useful mass spectrum. In this paper we use ODE, defined by the following equations:

$$
\begin{aligned}
& \mathrm{ODE}=\mathrm{SE} \times \mathrm{HR} \times 100 \% \\
& \mathrm{SE}=N_{d} / N_{0} \times 100 \% \text { (transmission efficiency } \\
& \quad \text { of } \mathrm{ADL} \text { is included), } \\
& \mathrm{HR}=N_{s} / N_{d} \times 100 \% \text { (ionization efficiency } \\
& \quad \text { is included), } \\
& N_{0}=C_{n} \times \text { flow rate } \times \text { time },
\end{aligned}
$$

where $N_{d}$ is the number of particles detected by light scattering, $N_{0}$ is the number of particles in front of the ADL, $N_{s}$ is the number of bipolar spectra, $C_{n}$ is the particle number concentration $\left(\mathrm{cm}^{-3}\right)$ measured by a CPC in front of the ADL, and the flow rate is the LAAPTOF sample flow rate.

\subsection{Spectral and size data analysis}

For each type of laboratory-generated aerosol particles, we measured at least 300 mass spectra. Data analysis is done via the Igor LAAPTOF data analysis software (version 1.0.2, AeroMegt $\mathrm{GmbH}$ ). There are five main steps for the basic analysis procedure: (a) removal of the excimer laser ringing signal from the raw mass spectra; (b) determination of the signal baseline; (c) filtering for empty spectra; (d) mass calibration; and (e) stick integration, that is, the integration of nominal masses for peaks. It should be noted that spectrum-to-spectrum differences in peak positions for the same ion fragments/clusters complicate the mass calibrations. This may be caused by differences in kinetic energy of the ions produced; however this effect is typically compensated in the TOFs with reflectron (Kulkarni et al., 2011). Spectrum-to-spectrum peak shifts, especially in the positive spectra in our study, are mainly because of variance in the position of particle-laser interaction, which cannot be corrected with the existing AeroMegt software or the LAAPTOF instrument (Ramisetty et al., 2017). Details can be found in "Procedure 1" in the Supplement. Spectra presented in this paper were typically normalized to the sum of ion signal before further aggregation.

For ambient data analysis, we used two different classification methods. The first one is fuzzy $c$-means clustering algorithm embedded in the Igor LAAPTOF data analysis software, commonly used to do classification based on the similarities of the individual spectra. The number of the classes is chosen manually; afterwards the particle spectra with a minimum distance between their data vectors and a cluster centre are grouped into a specific class (Hinz et al., 1999; Reitz et al., 2016). Since each spectrum can belong to multiple classes (Reitz et al., 2016), the resulting fraction/percentage for each class represents the information about the degree of 
similarity between aerosol particles in one particular class, not a number percentage. The second method developed in this study is based on the correlation between each ambient spectrum and our reference spectra. The resulting Pearson's correlation coefficient $(r)$ is used as the criterion to group particles into different types (here we use "types" instead of "classes" in order to differentiate these two classification methods). When $r$ is higher than a threshold value of 0.6 , the ambient spectrum is considered to have high correlation with the corresponding reference spectrum. For simplification we chose 10 positive and 7 negative reference spectra. For example, we only use German soil dust as the reference for arable soil dust, rather than using four arable soil dust samples from different places. More details about the procedure for this method as well as the corresponding equations and uncertainties estimation can be found in "Procedure 2" in the Supplement.

In addition, particle size $\left(d_{\mathrm{va}}\right)$ was recorded for individual particles. The corresponding size distribution can be plotted as $d_{\mathrm{va}}$ histogram, a Gaussian fit of which yields number mean $d_{\mathrm{va}}$ values and the standard deviation (width).

\section{Results and discussion}

\subsection{LAAPTOF performance}

\subsubsection{Hit rate, scattering efficiency, and overall detection efficiency for standard samples}

HR, SE, and ODE for spherical PSL particles as a function of electrical mobility equivalent diameter $d_{\mathrm{m}}$ are plotted in Fig. 2. It should be noted that the LAAPTOF detection behaviour may vary depending on the alignment of the ADL and the optical components (especially the detection laser diodes), which is difficult to reproduce. We therefore show results for PSL particles based on two repeated experiments after three alignments each and thus a total of six experiments for each data point. The uncertainty intervals in Fig. 2 are the difference between the maximum/minimum and the average values obtained from these six experiments. As shown in panel a of Fig. 2, for particle diameters from 200 to $400 \mathrm{~nm}$, HR $_{\text {PSL }}$ exhibits an increase from 69 to $94 \%$, decreases to $83 \%$ for $700 \mathrm{~nm}$ particles, and then becomes stable at $\sim 85 \%$ for particles with diameters up to $2 \mu \mathrm{m}$. The average HRPSL ( $\overline{\mathrm{HR}}_{\mathrm{PSL}}$ ) is $\sim 84 \%$. SEPSL and ODEPSL show an M-like shape with two peaks, at $500 \mathrm{~nm}$ (SEPSL $3.0 \%$, ODE $2.7 \%$ ) and at $1000 \mathrm{~nm}\left(\mathrm{SE}_{\mathrm{PSL}} 4.8 \%\right.$, ODE $\mathrm{PSL} 4.2 \%$ ) (see panels b and c of Fig. 2). We attribute this behaviour to a combined effect of the spherical shape of PSL particles and the optical system of this instrument, e.g. Mie resonances related to particle size and laser wavelength (see Sect. 3.1.2 for details). As shown in panel $\mathrm{c}$ of Fig. 2, values and trends of ODE $_{P S L}$ in the size range of $300-800 \mathrm{~nm}$ of our instrument are similar to those reported by Gemayel et al. (2016) and
Marsden et al. (2016) for their LAAPTOF instruments. A recent LAAPTOF study by Zawadowicz et al. (2017) shows comparable results for PSL particles with $d_{\mathrm{p}} \leq 500 \mathrm{~nm}$ and an M-like shape of ODE in the size range of $200-2000 \mathrm{~nm}$ (after instrument modification).

We also measured mass spectra of non-spherical $\mathrm{NH}_{4} \mathrm{NO}_{3}$ $(\chi=0.8$; Williams et al., 2013) and $\mathrm{NaCl}$ particles (cubic, $\chi=1.06$ to 1.17 ; Zelenyuk et al., 2006a). Similar to PSL particles, $\mathrm{NH}_{4} \mathrm{NO}_{3}$ and $\mathrm{NaCl}$ particles show relatively high and stable HR with average values of 80 and $66 \%$ (see panel d in Fig. 2); thus SE and ODE have a similar trend. No M-like shape of ODE as a function of particle size is observed due to the different light scattering properties of the non-spherical salt particles (Bohren and Huffman, 2007; see panels e and $\mathrm{f}$ in Fig. 2). Comparable results were shown for $\left(\mathrm{NH}_{4}\right)_{2} \mathrm{SO}_{4}$ particles $(\chi=1.03$ to 1.07 ; Zelenyuk et al., 2006a) by Zawadowicz et al. (2017). As shown in Fig. 2e-f, SE and ODE decrease with increasing shape factor for salt particles of the same size. We will discuss this in more detail in the following section.

\subsubsection{Factors influencing overall detection efficiency}

There are various factors that can influence the ODE of LAAPTOF. One of these is particle size. For particles with diameters below $200 \mathrm{~nm}$, the scattered light becomes too weak to be detected due to the strong dependence of the scattering intensity on particle size (Bohren and Huffman, 2007). For particles with diameters larger than $2 \mu \mathrm{m}$, focusing by the ADL is much less efficient, resulting in a higher divergence of the particle beam (Schreiner et al., 1999). This lowers the probability of larger particles being detected by the detection/scattering laser and/or being hit by the ionization laser. In addition, light scattering of spherical particles like PSL changes from Rayleigh to Mie to geometric scattering as the size parameter $\alpha=\pi d_{\mathrm{p}} / \lambda$ increases from $\ll 1$ to $\sim 1$ to $\gg 1$ (Seinfeld and Pandis, 2006). The scattering efficiencies of PSL particles, based on Mie calculation at the particle sizes and detection laser wavelength relevant to our LAAPTOF measurement, validate the M-like shape of $\mathrm{SE}_{\mathrm{PSL}}$ (refer to Fig. S1 in the Supplement). As long as the particle diameter $\left(d_{\mathrm{p}}\right)$ is smaller than the wavelength of the detection laser light, here $405 \mathrm{~nm}$, the scattered-radiation intensity (proportional to $d_{\mathrm{p}}^{6}$ ) will rapidly decrease with decreasing particle sizes, resulting in low ODE. ODE is e.g. $0.01 \%$ for $200 \mathrm{~nm}$ PSL particles. For non-spherical particles like salts, their SE and ODE are also size dependent (panel $\mathrm{f}$ in Fig. 2), due to size-dependent light scattering ability and particle beam divergence. However, in the size range of 300 to $1000 \mathrm{~nm}$ studied here, they do not exhibit Mie resonance and thus do not show an M-like shape in their scattering efficiency.

Optical properties of the particles have a strong impact on how light is scattered and absorbed, and thus it should be noted that the optical properties influence not only scattering efficiency but also absorption and ionization efficiency (or hit 


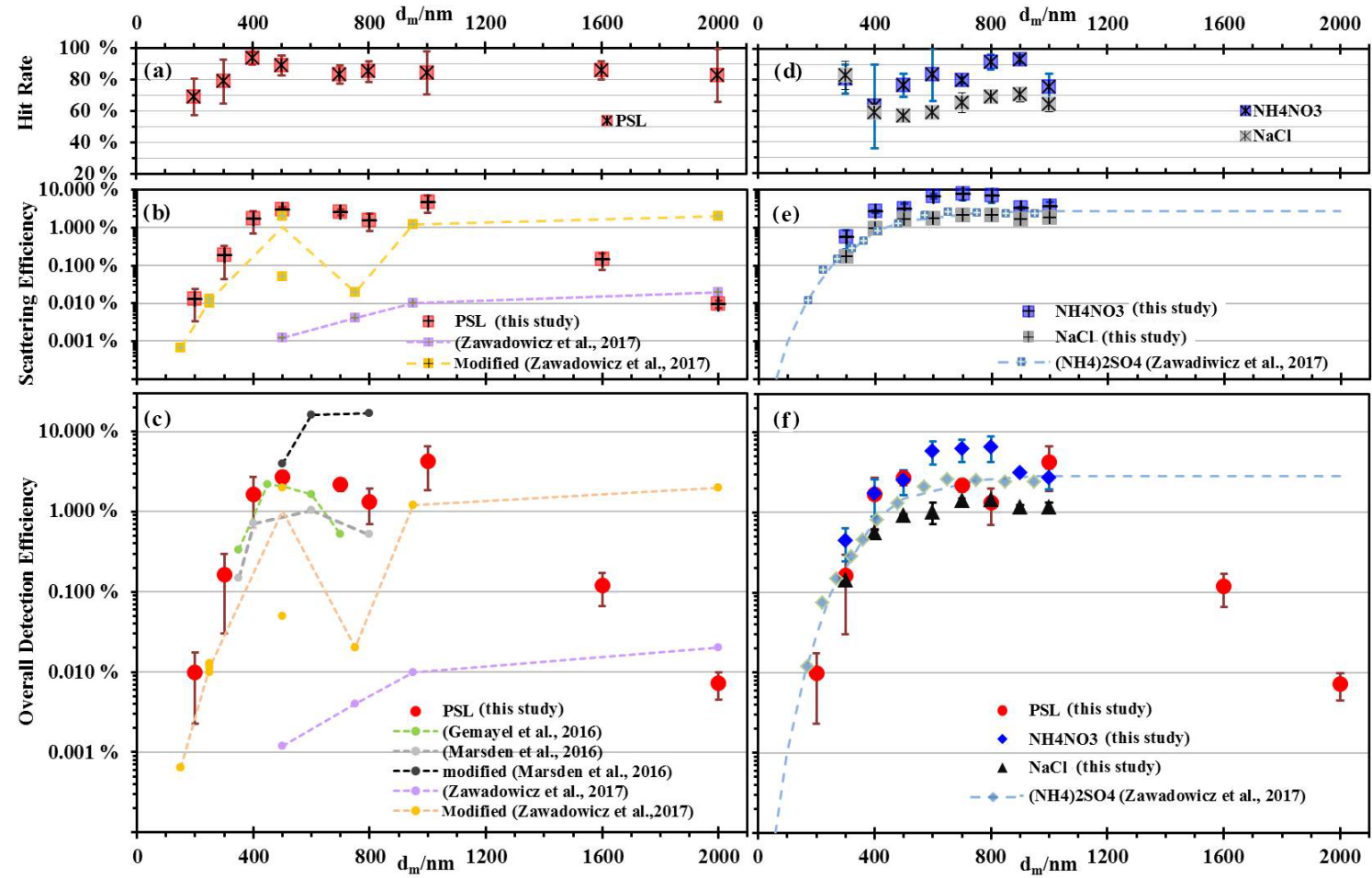

Figure 2. Hit rate (HR, a and d), scattering efficiency (SE, b and e), and overall detection efficiency (ODE, $\mathbf{c}$ and $\mathbf{f}$ ) for PSL, ammonium nitrate $\left(\mathrm{NH}_{4} \mathrm{NO}_{3}\right)$, and sodium chloride $(\mathrm{NaCl})$ salt particles as a function of mobility diameter, $d_{\mathrm{m}}$. Aerosol particles in this study were generated from a nebulizer and size-selected by DMA. In (b) and (e), OCEs for PSL and ammonium sulfate $\left(\left(\mathrm{NH}_{4}\right)_{2} \mathrm{SO}_{4}\right)$ at the detection beam from the study by Zawadowlcz et al. (2017), corresponding to the SE defined in this study, are plotted for comparison. In (c) and (f), ODE for PSL and salt particles from other studies (Gemayel et al., 2016; Marsden et al., 2016; Zawadowicz et al., 2017) are plotted for comparison. In this figure, dashed lines are used only to guide the eyes.

rate). As shown in Fig. 2f, ODE for $\mathrm{NH}_{4} \mathrm{NO}_{3}$ is higher than that for $\mathrm{NaCl}$ at any size we studied. This is mainly caused by differences in their optical properties of scattering. Fresh soot particles scatter only little light due to their black colour and the small size (typically $\sim 20 \mathrm{~nm}$ ) of the primary particles forming their agglomerates, and are thus hardly detected by the detection laser. However they are good light absorbers and thus relatively easy to ablate and ionize. The reference spectra of pure $\mathrm{NH}_{4} \mathrm{NO}_{3}$ and $\left(\mathrm{NH}_{4}\right)_{2} \mathrm{SO}_{4}$ particles showed intensive prominent peaks for pure $\mathrm{NH}_{4} \mathrm{NO}_{3}$ particles (refer to Fig. 3a) but only one weak peak of $m / z 30 \mathrm{NO}^{+}$for pure $\left(\mathrm{NH}_{4}\right)_{2} \mathrm{SO}_{4}$ particles. This indicates that $\mathrm{NH}_{4} \mathrm{NO}_{3}$ is a better absorber than $\left(\mathrm{NH}_{4}\right)_{2} \mathrm{SO}_{4}$ and thus easier to ablate and ionize. For homogeneous mixtures of these two ammonium salts, the sulfate species are ablated and ionized much more easily (refer to Sect. 3.2.2), due to increased UV light absorption by the nitrate component. Some small organic compounds with weak absorption properties are hard to ablate and ionize, e.g. oxalic acid $\left(\mathrm{C}_{2} \mathrm{H}_{2} \mathrm{O}_{4}\right)$, pinic acid, and cispinonic acid. They exhibited much weaker signals $(\sim 80 \%$ lower) than macromolecular organic compounds in PSL or humic acid particles.
Particle morphology is another important factor. The scattering efficiency for non-spherical $\mathrm{NH}_{4} \mathrm{NO}_{3}$ is higher than for spherical PSL particles in the size range of $300-800 \mathrm{~nm}$ (Fig. 2b-e) (Ackerman et al., 2015). For larger particle sizes $\left(d_{\mathrm{m}}>800 \mathrm{~nm}\right)$, beam divergence offsets the shape effect (Murphy, 2007). Apart from that, the increase of surface roughness and inhomogeneity can promote the scattering capability of particles (Ackerman et al., 2015).

The incident intensity of radiation, which is another parameter that influences the light scattered by particles (as well as background signal caused by stray light), is related to power and beam dimensions of the detection laser. Corresponding instrument modifications were done by Marsden et al. (2016) and Zawadowicz et al. (2017) (refer to Sect. 1). In addition, alignment of the excimer laser focus in the $x, y$, and $z$ position influences optimum hit rates (Ramisetty et al., 2017).

There are further instrumental aspects that affect the detection efficiency. High number concentrations of the incoming particles influence the ODE, since there can be more than one particle present between the two detection lasers. The transmission efficiency of the ADL is included in the scattering efficiency and thus directly influences it. The size 

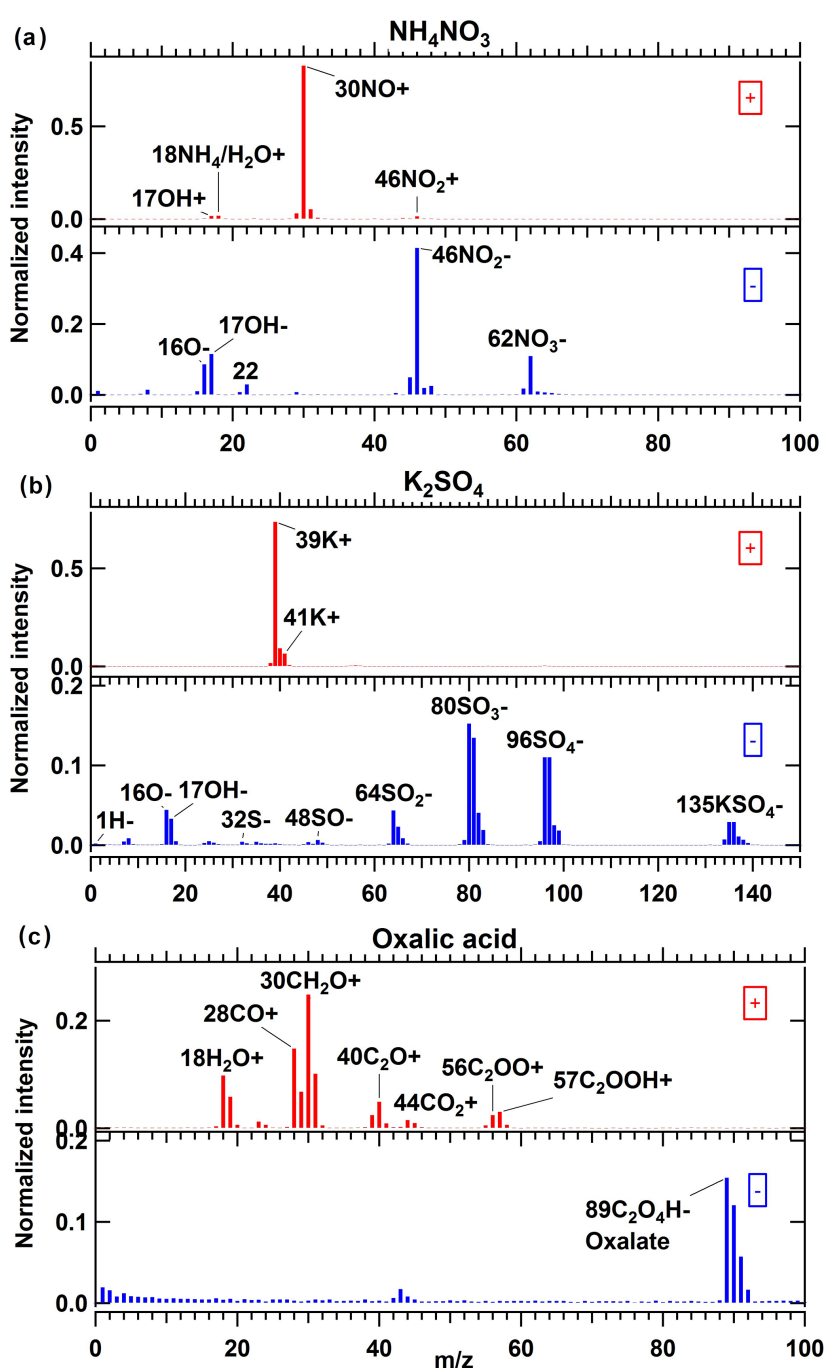

Figure 3. Average mass spectra for pure compound aerosol particles: (a) $\mathrm{NH}_{4} \mathrm{NO}_{3}\left(d_{\mathrm{va}}=1160 \mathrm{~nm}\right), 497$ single spectra averaged; (b) $\mathrm{K}_{2} \mathrm{SO}_{4}\left(d_{\mathrm{va}}=1465 \mathrm{~nm}\right), 300$ single spectra averaged; and (c) oxalic acid particles $\left(d_{\mathrm{va}}=1081 \mathrm{~nm}\right), 736$ single spectra averaged.

range of particles focused by the lens and the particle beam width strongly depend on the configuration of the ADL (Canagaratna et al., 2007; Johnston, 2000). Liu lenses and Schreiner lenses can focus the particles in the size range of 80-800 and 300-3000 $\mathrm{nm}$, respectively (Kamphus et al., 2008; Liu et al., 1995; Schreiner et al., 1999). The ADL transmission efficiency of our instrument, as determined by the manufacturer (AeroMegt $\mathrm{GmbH}$ ), is close to $100 \%$ for particles with $d_{\text {va }} 100-2000 \mathrm{~nm}$.

\subsection{LAAPTOF reference spectra of laboratory-generated particle types}

Particles for which reference spectra are presented here are listed in Table 1. For each type of these aerosol particles, we present averaged spectra for typically 300 to 500 single particles. The relative standard deviations (RSDs, SD normalized to signal) for the characteristic peaks are in the range of 15 $186 \%$, with a median value of $77 \%$.

Despite the lack of full quantitativeness of the LAAPTOF, mass spectral signal amplitudes show an increase with particle size (refer to Fig. S2). However, no systematic changes in the mass spectral signatures were observed for different particle sizes. Therefore, for the samples passing through the DMA, particles in the optimum size range of the LAAPTOF $\left(d_{\mathrm{m}}=800 \mathrm{~nm}\right)$ and with good signal-to-noise ratio were chosen to generate reference spectra. For polydisperse particles generated in the AIDA chamber, the corresponding average spectra include particles of broader size distributions than those preselected by the DMA. Information on particle generation or source as well as the sizes is listed in Table 1.

A qualitative comparison between the relative peak intensity ratios within a single-particle spectrum and those in another spectrum can yield relative quantitation information, as suggested by Gross et al. (2000). We add information on typical peak ratios to some of our reference spectra to help identify specific species.

\subsubsection{Pure compound particles}

Although particles consisting of one single species only are rarely sampled in the atmosphere, interpretation of mass spectra of ambient samples is supported by the knowledge about the mass spectra of pure compounds. In the following, mass spectra for a few typical ambient aerosol constituents are discussed.

Figure 3 shows average spectra for pure compound aerosol particles. For $\mathrm{NH}_{4} \mathrm{NO}_{3}$ particles (panel a), we observed the positive ions $m / z 18 \mathrm{NH}_{4}^{+}$and $m / z 30 \mathrm{NO}^{+}$, and the negative ions $m / z 46 \mathrm{NO}_{2}^{-}$and $m / z 62 \mathrm{NO}_{3}^{-}$, similar to Reitz et al. (2016). The LAAPTOF is much less sensitive to ammonium than nitrate fragments, leading to a weak $\mathrm{NH}_{4}^{+}$signal and prominent $\mathrm{NO}^{+}, \mathrm{NO}_{2}^{-}$and $\mathrm{NO}_{3}^{-}$peaks. The ratio of $\mathrm{NO}^{+}$to $\mathrm{NH}_{4}^{+}$is $\sim 48$, and the ratio of $\mathrm{NO}_{2}^{-}$to $\mathrm{NO}_{3}^{-}$is $\sim 4$. The prominent peak of $\mathrm{NO}^{+}$arises not only from nitrate (majority), but also from ammonium (Murphy et al., 2006). In our ammonium nitrate spectra, there are weaker signatures of $m / z 46 \mathrm{NO}_{2}^{+}$and $m / z 125 \mathrm{HNO}_{3} \cdot \mathrm{NO}_{3}^{-}$(not shown here, but visible and reproducible), which were also observed in PALMS mass spectra (Zawadowicz et al., 2015). For $\mathrm{K}_{2} \mathrm{SO}_{4}$ particles, we observed the potassium signals at $m / z 39 \mathrm{~K}^{+}$ and $m / z 41 \mathrm{~K}^{+}$, and a sulfate signature with ion clusters grouped around $m / z 32 \mathrm{~S}^{-}, m / z 64 \mathrm{SO}_{2}^{-}, m / z 80 \mathrm{SO}_{3}^{-}$, and $m / z 96 \mathrm{SO}_{4}^{-}$. Note that the extra peak at $m / z 40^{+}$besides $m / z 39 \mathrm{~K}^{+}$in Fig. $3 \mathrm{~b}$ is likely due to the incorrect mass as- 
signments as a result of peak shifts (refer to Sect. 2.5 and "Procedure 1" in the Supplement). For high-intensity peaks such as sodium chloride $\mathrm{NaCl}$, extra peaks next to the main peak (Fig. S3) may have an additional cause: "ringing" due to partial saturation of the data acquisition system or signal reflections within the data acquisition circuitry (Gross et al., 2000). The real intensities of $m / z 35 \mathrm{Cl}^{-}$should include its corresponding side ringing peak. The ratio of $m / z 39 \mathrm{~K}^{+}$to $m / z 41 \mathrm{~K}^{+}$is $\sim 13.2$, close to the natural isotopic ratio of $\sim 13.9$ for ${ }^{39} \mathrm{~K} /{ }^{41} \mathrm{~K}$. For pure $\mathrm{NaCl}$ particles, the ratio of $m / z 35 \mathrm{Cl}^{-}$to $m / z 37 \mathrm{Cl}^{-}$is $\sim 3.2$, similar to the natural isotopic ratio of $\sim 3.1$ for ${ }^{35} \mathrm{Cl} /{ }^{37} \mathrm{Cl}$. Therefore, these two isotopic ratios can be used as markers to identify $\mathrm{K}$ and $\mathrm{Cl}$ measured by LAAPTOF. Another inorganic compound measured here is silica (Fig. S4), and its typical peak ratio of $(\mathrm{m} / \mathrm{z} 76$ $\mathrm{SiO}_{3}^{-}+m / z 77 \mathrm{HSiO}_{3}^{-}$) to $m / z 60 \mathrm{SiO}_{2}^{-}$is $\sim 1.0$. The corresponding histograms of such ratios for different particle samples can be found in Fig. S5.

High signal intensities in oxalic acid spectra are observed at $m / z 18 \mathrm{H}_{2} \mathrm{O}^{+}, 28 \mathrm{CO}^{+}$, and $30 \mathrm{CH}_{2} \mathrm{O}^{+}$, as well as some weaker peaks at $m / z 40^{+}, 44^{+}, 56^{+}$, and $57^{+} . M / z 89$ $\mathrm{C}_{2} \mathrm{O}_{4} \mathrm{H}^{-}$is used as a signature ion for oxalic acid in other SPMS studies (Roth et al., 2016). In our study, a distinct signal at around $m / z 89^{-}$is observed as well, indicating oxalate fragment formation after laser ablation.

In order to identify humic-like substances in the ambient particles, we measured humic acid particles (Fig. S6) and found hydrocarbon and elemental carbon fragments, with very prominent peaks at $\mathrm{m} / \mathrm{z} 24^{-}, 25^{-}$, and $26^{-}$suggested to be organic ions (Silva et al., 2000), as well as peaks at $m / z 25^{-}, 26^{-}, 49^{-}$, and $73^{-}$for unsaturated organic compounds.

\subsubsection{Particles consisting of well-defined internal mixtures}

Figure 4 shows average spectra from homogeneously internally mixed particles. The spectrum from the mixture of $\mathrm{NH}_{4} \mathrm{NO}_{3}$ and $\left(\mathrm{NH}_{4}\right)_{2} \mathrm{SO}_{4}$ (panel a) contains the signature from pure $\mathrm{NH}_{4} \mathrm{NO}_{3}$ particles, but with lower relative intensities (each peak intensity is normalized to the sum of ion signal) for $\mathrm{NO}_{2}^{-}$and $\mathrm{NO}_{3}^{-}$, due to the formation of anion clusters at $\sim m / z=80 \mathrm{SO}_{3}^{-}$and $97 \mathrm{HSO}_{4}^{-}$. Compared to the pure $\mathrm{NH}_{4} \mathrm{NO}_{3}$ particles, the ratio of $\mathrm{NO}^{+}$to $\mathrm{NH}_{4}^{+}(\sim 34)$ is $\sim 30 \%$ lower in the spectrum for the mixture, due to its lower molar ratio of nitrate to ammonium, whereas the ratio of $\mathrm{NO}_{2}^{-}$to $\mathrm{NO}_{3}^{-}(\sim 7)$ is $80 \%$ higher. In addition, as already discussed in Sect. 3.1.2, the better UV light absorber $\mathrm{NH}_{4} \mathrm{NO}_{3}$ assists in light absorbing for mixed particles, resulting in a sulfate signature that could not be observed for pure $\left(\mathrm{NH}_{4}\right)_{2} \mathrm{SO}_{4}$. This exemplifies potential effects of individual particle chemical composition on mass spectral performance of the LAAPTOF. For the mixture of $\mathrm{K}_{2} \mathrm{SO}_{4}$ and $\mathrm{NaCl}$ (panel b), similar signatures to those of the pure particles were observed. Compared to the pure $\mathrm{NaCl}$ particle spectra, the signal intensity of $\mathrm{Na}^{+}$is decreased. This can be explained by more cations formed from the mixed particles, including from potassium, which has a higher ionization potential and lower lattice energy than $\mathrm{NaCl}$. For the mixed particles, expected clusters such as $113 / 115 \mathrm{~K}_{2} \mathrm{Cl}^{+}, 109 \mathrm{KCl}_{2}^{-}$, and $119 \mathrm{NaSO}_{4}^{-}$and a minor fragment $97 \mathrm{KNaCl}^{+}$were observed, but not $81 / 83 \mathrm{Na}_{2} \mathrm{Cl}^{+}$as found in pure $\mathrm{NaCl}$ particles. These results show that, compared to pure compounds, mass spectra from aerosol particles consisting of mixtures can feature new ions, while some marker ions for the pure compounds may disappear. These spectra are thus not simply a combination of the spectra from single-component particles. Another example of an inorganic mixture of $\mathrm{NH}_{4} \mathrm{NO}_{3}$ and $\mathrm{K}_{2} \mathrm{SO}_{4}$ is provided in Fig. S7. The $\alpha$-pinene SOA spectrum is shown in panel $\mathrm{c}$ of Fig. 4. Ablation of $\alpha$-pinene SOA particles forms different types of organic fragments: (1) hydrocarbon and oxygenated organic fragments $\mathrm{C}_{x} \mathrm{H}_{y} \mathrm{O}_{z}$ ( $x=1-6, y=0-9, z=0-3$; details about the peak assignments can be found in Table S1) - except for $m / z 59^{+}$, $83^{+}, 85^{+}$, and $95^{+}-$are comparable to the combination mass spectral patterns for $c i s$-pinonic and pinic acids (refer to Fig. S8), which are oxidation products from $\alpha$-pinene ozonolysis (Saathoff et al., 2009; Yu et al., 1999); (2) carbon clusters $12 \mathrm{C}^{+}, 24 \mathrm{C}_{2}^{+}, 36 \mathrm{C}_{3}^{+}$, and $60 \mathrm{C}_{5}^{+}$, with the most prominent peak in $12 \mathrm{C}^{+}$, assigned to both soot and organic matter fragments in another LAAPTOF study (Ahern et al., 2016); and (3) carboxylic acid groups in the negative spectra, e.g. $45 \mathrm{COOH}^{-}, 59 \mathrm{CH}_{2} \mathrm{COOH}^{-}, 73 \mathrm{C}_{2} \mathrm{H}_{4} \mathrm{COOH}^{-}, 85$ $\mathrm{C}_{3} \mathrm{H}_{4} \mathrm{COOH}^{-}$, and $99 \mathrm{C}_{4} \mathrm{H}_{6} \mathrm{COOH}^{-}$.

Figure 5a shows the spectrum for heterogeneously internally mixed $\mathrm{K}_{2} \mathrm{SO}_{4}$ and PSL particles (PSL core, $\mathrm{K}_{2} \mathrm{SO}_{4}$ shell). All signatures for PSL particles - i.e. hydrocarbon fragments in positive spectra; intensive organic signature $\mathrm{m} / \mathrm{z} 24^{-}, 25^{-}$, and $26^{-}$; carbon clusters $\mathrm{C}_{n}^{+/-}$; and $\mathrm{m} / \mathrm{z} 49^{-}$ and $73^{-}$fragments arising from unsaturated structures such as aromatic structures - are retained in this spectra (grey labels), and the corresponding peak intensities are similar to the pure PSL particles (Fig. S9). However, the intensities of most of the $\mathrm{K}_{2} \mathrm{SO}_{4}$ fragments are weaker than pure $\mathrm{K}_{2} \mathrm{SO}_{4}$ particles, likely due to the quite thin or only partial coating layer of $\mathrm{K}_{2} \mathrm{SO}_{4}$ on the PSL core (the nominal geometric size of the PSL particles mixed with the aqueous solution of $\mathrm{K}_{2} \mathrm{SO}_{4}$ was $800 \mathrm{~nm}$, which is the same size that was selected by the DMA prior to sampling by the mass spectrometer.). The most prominent peak at $m / z 39^{+}$with a normalized intensity of $\sim 0.46$, containing both $\mathrm{K}^{+}$and $\mathrm{C}_{3} \mathrm{H}_{3}^{+}$ fragments, is mainly attributed to $\mathrm{K}^{+}$(intensity $\sim 0.73$ for pure $\left.\mathrm{K}_{2} \mathrm{SO}_{4}\right)$, since the intensity of $\mathrm{C}_{3} \mathrm{H}_{3}^{+}(\sim 0.06)$ for pure PSL is much lower (refer to Fig. S9). The still intensive signal from $39 \mathrm{~K}^{+}$, despite the weaker sulfate peaks, corresponds to the high sensitivity of the instrument to potassium. Figure $5 \mathrm{~b}$ shows the average spectrum for poly(allylamine hydrochloride)-coated gold particles. Prominent signatures of nitrogen-containing compounds (NOCs) are observed at $m / z 58 \mathrm{C}_{2} \mathrm{H}_{5}-\mathrm{NH}-\mathrm{CH}_{2}^{+}, 15 \mathrm{NH}^{+}, 26 \mathrm{CN}^{-}$, and $42 \mathrm{CNO}^{-}$, 

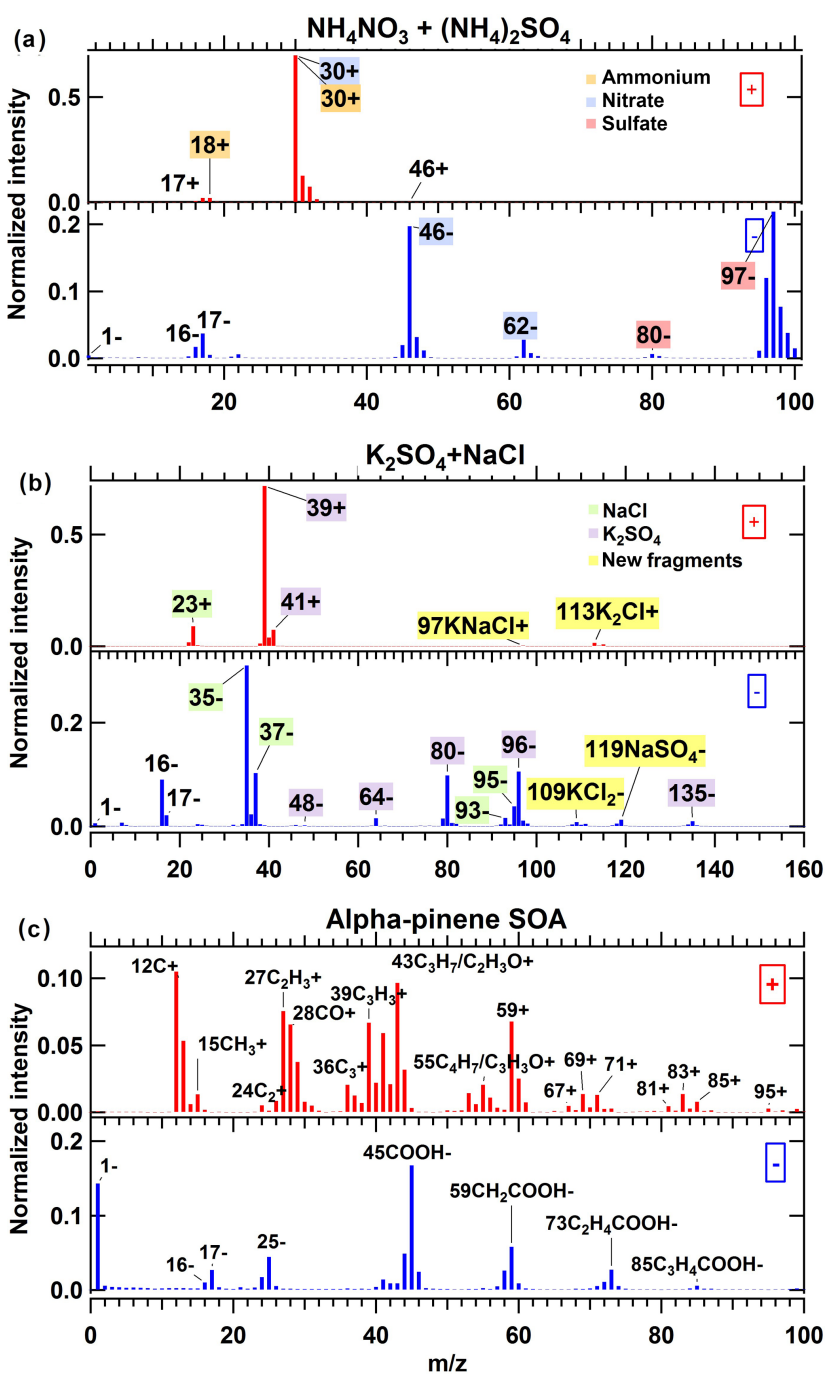

Figure 4. Average mass spectra for particles of internal mixtures of (a) $\mathrm{NH}_{4} \mathrm{NO}_{3}$ and $\left(\mathrm{NH}_{4}\right)_{2} \mathrm{SO}_{4}\left(d_{\mathrm{va}}=1102 \mathrm{~nm}\right), 454$ single spectra averaged, and (b) $\mathrm{NaCl}$ and $\mathrm{K}_{2} \mathrm{SO}_{4}\left(d_{\mathrm{va}}=1375 \mathrm{~nm}\right), 259$ single spectra averaged, as well as (c) secondary organic aerosol (SOA) particles from $\alpha$-pinene ozonolysis, which was performed in the APC chamber, and then the resulting particles were transferred into the AIDA chamber at $263 \mathrm{~K}$ and $95 \% \mathrm{RH}, d_{\mathrm{va}}=505 \mathrm{~nm}, 1938$ single spectra averaged. In (a), red, blue, and orange label shadings represent fragments of sulfate, nitrate, and ammonium, respectively. In (b), green and purple label shadings represent fragments from $\mathrm{NaCl}$ and $\mathrm{K}_{2} \mathrm{SO}_{4}$ components (see Sect. 3.2.1) in the mixed particles, respectively; yellow label shadings represent the fragments only in the internal mixture of $\mathrm{NaCl}$ and $\mathrm{K}_{2} \mathrm{SO}_{4}$.

as well as the signatures for unsaturated organic compounds at $m / z 25^{-}, 26^{-}, 49^{-}$, and $73^{-}$. Strong intensities for $m / z$ $\left(35^{-}\right.$plus $\left.36^{-}\right)$and $37^{-}$with a ratio of $\sim 3.1$ can be assigned to $\mathrm{Cl}$ isotopes derived from the hydrochloride. We also observed small gold peaks at $m / z 197^{+/-}$both in positive and negative spectra.
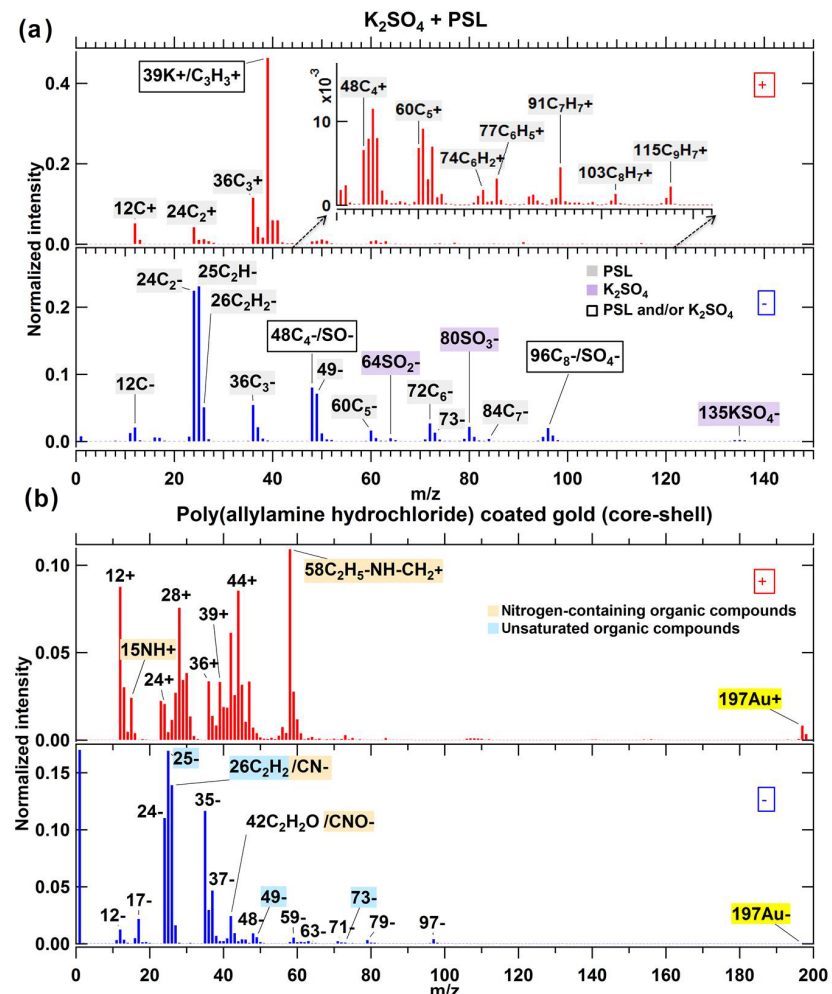

Figure 5. Average mass spectra for core-shell particles of (a) PSL coated with $\mathrm{K}_{2} \mathrm{SO}_{4}, d_{\mathrm{va}}=805 \mathrm{~nm}, 609$ single spectra averaged, and (b) poly(allylamine hydrochloride)-coated gold ( $\mathrm{Au}$ ) particles with geometric $300 \mathrm{~nm}$ gold core and $50 \mathrm{~nm}$ thick organic shell, 417 single spectra averaged. In (a), grey and purple label shadings represent the fragments arising from pure PSL and pure $\mathrm{K}_{2} \mathrm{SO}_{4}$ components, respectively; box labels represent the fragments with contributions from core and shell compounds. In (b) orange and blue label shadings represent the fragments arising from nitrogen-containing and unsaturated organic compounds, respectively, and yellow label shadings represent gold.

Mass spectra for other well-defined compounds, i.e. synthetic hematite and pure sea salt particles, are also provided in the Supplement (Figs. S10 and S11).

\subsubsection{Particles consisting of complex mixtures}

Figure 6 shows the average spectra for different types of soot particles. All of them show characteristic patterns for elemental carbon (EC) $\mathrm{Cn}^{+/-}$. For soot 1 with high organic carbon (OC) content from propane combustion in the laboratory (panel b), prominent peaks were observed at $\mathrm{m} / z 28 \mathrm{CO}^{+}$ and $27 \mathrm{C}_{2} \mathrm{H}_{3}^{+}$, as well as some other organic carbon signatures at $m / z 39^{+}, 40^{+}, 44^{+}$, and $56^{+}$. All the organic signatures in soot 1 with high OC were also observed for soot 3 , lignocellulosic char from chestnut wood (panel d), indicating that biomass burning soot contains a significant fraction of OC. It should be noted that biomass burning will also form potassium; thus $m / z 39^{+}$contains both $\mathrm{K}^{+}$and $\mathrm{C}_{3} \mathrm{H}_{3}^{+}$frag- 
(a),, 1, , Soot 1 with low organic carbon,

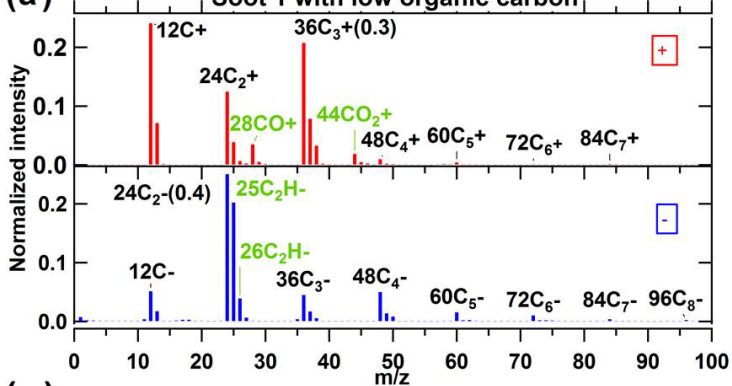

(c)

Soot 2: Diesel particles NIST

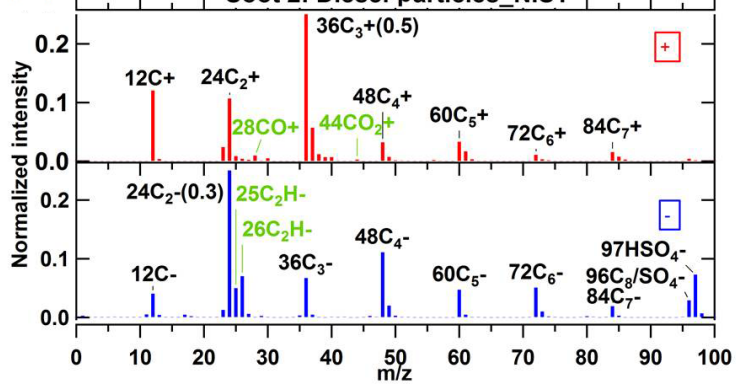

(b) $\leftarrow, 1$, Soot 1 with high organic carbon

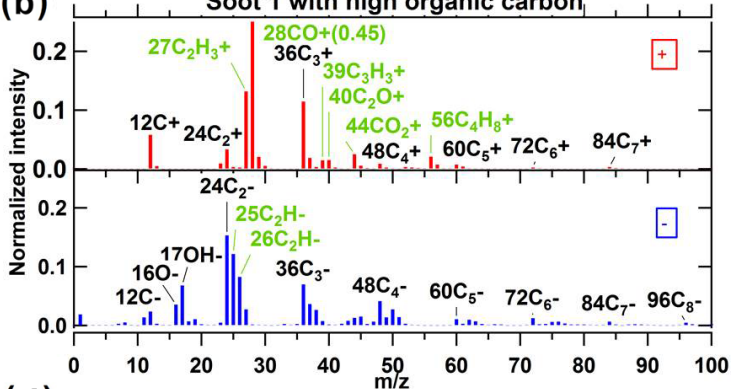

(d)

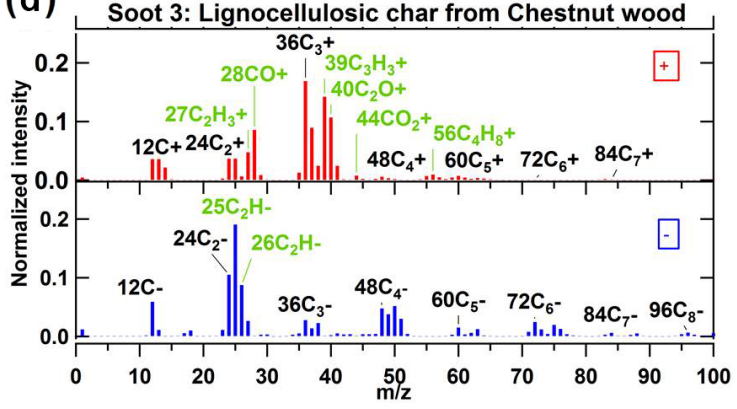

Figure 6. Average mass spectra for soot particles with (a) high elemental carbon (EC) and low organic carbon (OC) content, and (b) low EC and high OC from combustion of propane in a soot generator and transferred to a stainless-steel cylinder of $\sim 0.2 \mathrm{~m}^{3}$ volume, as well as soot particles of (c) diesel particles (NIST) and (d) lignocellulosic char from chestnut wood. In (a) and (c), the numbers in brackets beside peak $36^{+}$and $24^{-}$are the exact intensity values for them. The OC signatures are labelled in green. The numbers of spectra averaged for each spectrum are 617 (a), 347 (b), 533 (c) and 390 (d).

ments. $M / z 24^{-}, 25^{-}$, and $26^{-}$can be observed in all the soot types, but with slightly different patterns: (1) soot with high EC content shows very high $m / z 24^{-}$( $\sim 2$ to 3 times that of $m / z 25^{-}$), while (2) soot with high OC shows comparable or even higher $m / z 25^{-}$to/than $m / z 24^{-}$. These patterns might help to distinguish EC and OC contributions in the spectra from ambient particles.

Figure 7 shows spectra for Arizona test dust (milled desert dust) (panel a), arable soil SDGe01 sampled from Gottesgabe in Germany (panel b), and agricultural soil dust collected from harvesting machines after rye and wheat harvest (panel c). For Arizona test dust, we observed high mineral signatures of aluminium- and silicon-containing clusters, namely $27 \mathrm{Al}^{+}, 28 \mathrm{Si}^{+}, 44 \mathrm{SiO}^{+}, 43 \mathrm{AlO}^{-}, 59 \mathrm{AlO}_{2}^{-}, 60 \mathrm{SiO}_{2}^{-}, 76$ $\mathrm{SiO}_{3}^{-}, 119 \mathrm{AlSiO}_{4}^{-}, 179 \mathrm{AlSiO}_{4} \cdot \mathrm{SiO}_{2}^{-}$, and $136\left(\mathrm{SiO}_{2}\right)_{2} \mathrm{O}^{-}$. It should be noted that high $16 \mathrm{O}^{-}$and $17 \mathrm{OH}^{-}$accompany the intensive mineral signatures, attributed to the adsorbed water on the active surface of mineral particles. In panel a, we also observed the following peaks: other mineral related metal clusters (e.g. $7 \mathrm{Li}^{+}, 23 \mathrm{Na}^{+}, 24 \mathrm{Mg}^{+}, 40 \mathrm{Ca}^{+}$, $39 / 41 \mathrm{~K}^{+}, 55 \mathrm{Mn}^{+}, 56 \mathrm{Fe}^{+}, 58 \mathrm{Ni}^{+}$, and $64 \mathrm{Zn}^{+}$); metal oxides and hydroxides (e.g. $56 \mathrm{CaO}^{+}, 57 \mathrm{CaOH}^{+}, 96 \mathrm{Ca}_{2} \mathrm{O}^{+}$, and $112(\mathrm{CaO})_{2}^{+}$, and $\left.88 \mathrm{FeO}_{2}^{-}\right)$; and weak anion clusters of organic signature $\left(m / z 24 \mathrm{C}_{2}^{-}, 25 \mathrm{C}_{2} \mathrm{H}^{-}, 26 \mathrm{C}_{2} \mathrm{H}_{2}^{-}\right.$, and $\left.42 \mathrm{C}_{2} \mathrm{H}_{2} \mathrm{O}^{-}\right)$, NOCs $\left(m / z 26 \mathrm{CN}^{-}\right.$and $\left.42 \mathrm{CNO}^{-}\right)$, chloride $\left(\mathrm{m} / \mathrm{z} 35^{-}\right.$and $\left.37^{-}\right)$, sulfate $\left(\mathrm{m} / \mathrm{z} 32^{-}, 48^{-}, 64^{-}, 80^{-}\right.$, and $\left.97^{-}\right)$, phosphate $\left(63 \mathrm{PO}_{2}^{-}\right.$and $79 \mathrm{PO}_{3}^{-}$), diacids (oxalate 89
$(\mathrm{CO})_{2} \mathrm{OOH}^{-}$and $\left.117(\mathrm{CO})_{3} \mathrm{OOH}^{-}\right)$, and an unknown fragment $m / z 148^{-} . M / z 26^{+}$in panels $\mathrm{b}$ and $\mathrm{c}$ is much higher than $m / z 24^{-}$and $25^{-}$, due to the contribution of CN fragments from NOCs. Similar signatures can also be observed in the spectra for Saharan dust (Fig. S12).

Most of the mineral and organic fragments of soil dust are similar to those of desert dust; however with different intensities - e.g. $m / z 24^{-}, 25^{-}, 26^{-}$, and $42^{-}$(labelled in green) - they are more intensive than those in desert dust, indicating higher organic compound content. Some peak ratios of fragments are similar across the different dust types; e.g. $40 \mathrm{Ca}^{+}$to $56 \mathrm{CaO}^{+}$is $2.2,1.1$, and 2 for desert dust, arable soil dust and agricultural soil dust, respectively. Compared with desert dust, there are different fragments from soil dust particles, e.g. EC patterns (labelled in grey), organic acids signatures (blue), ammonium signatures (orange), unsaturated organic fragments $\left(\mathrm{m} / \mathrm{z}^{4} 9^{-}\right.$and $\left.73^{-}\right)$, and some other unknown fragments (red). For arable soil dust particles, we also measured samples from Paulinenaue in Germany (SDPA01), Argentina (SDAr08), and Wyoming in the USA (SDWY01) (refer to Fig. S13). Dominant mass spectral peak patterns are similar across all soil dust samples. They are located at around $m / z 27^{+}, 39^{+}$, and $56^{+}$in the positive spectra, and $26^{-}, 42^{-}, 60^{-}$, and $76^{-}$in negative spectra. Less prominent but reproducibly detected are carboxylic acid groups (e.g. $\mathrm{COOH}^{-}$) and EC patterns. The German soil dust, however, contains more organic species than soil dust 
Table 2. Summary of mass spectral patterns.

\begin{tabular}{|c|c|c|c|}
\hline Species & $\begin{array}{l}\text { Signature peaks in } \\
\text { positive spectra }\end{array}$ & $\begin{array}{l}\text { Signature peaks in } \\
\text { negative spectra }\end{array}$ & $\begin{array}{l}\text { Typical peak ratios } \\
\text { histogram } x_{0} \text { (width }^{*}\end{array}$ \\
\hline potassium & $39 \mathrm{~K}^{+}, 41 \mathrm{~K}^{+}$ & & $I 39: I 41=\sim 13.5(0.9)$ \\
\hline calcium & $40 \mathrm{Ca}^{+}, 56 \mathrm{CaO}^{+}$ & & \\
\hline aluminium & $27 \mathrm{Al}^{+}$ & $43 \mathrm{AlO}^{-}, 59 \mathrm{AlO}_{2}^{-}$ & \\
\hline silicon & $28 \mathrm{Si}^{+}, 44 \mathrm{SiO}^{+}$ & $60 \mathrm{SiO}_{2}^{-}, 76 \mathrm{SiO}_{3}^{-}, 77 \mathrm{HSiO}_{3}^{-}$ & $\begin{array}{l}(I 76+I 77): I 60= \\
\sim 1.0(0.33)\end{array}$ \\
\hline \multirow[t]{2}{*}{ silicon $\&$ aluminium } & $27 \mathrm{Al}^{+}, 28 \mathrm{Si}^{+}, 44 \mathrm{SiO}^{+}$ & $\begin{array}{l}43 \mathrm{AlO}^{-}, 59 \mathrm{AlO}_{2}^{-} \\
60 \mathrm{SiO}_{2}^{-}, 76 \mathrm{SiO}_{3}^{-}\end{array}$ & \\
\hline & $\begin{array}{l}77 \mathrm{HSiO}_{3}^{-}, 119 \mathrm{AlSiO}_{4}^{-} \\
179 \mathrm{AlSiO}_{4} \cdot \mathrm{SiO}_{2}^{-}\end{array}$ & & \\
\hline ammonium & $18 \mathrm{NH}_{4} / \mathrm{H}_{2} \mathrm{O}^{+}, 30 \mathrm{NO}^{+}$ & & \\
\hline nitrate & $30 \mathrm{NO}^{+}$ & $46 \mathrm{NO}_{2}^{-}, 62 \mathrm{NO}_{3}^{-}$ & \\
\hline sulfate & & $\begin{array}{l}32 \mathrm{~S}^{-}, 48 \mathrm{SO}^{-}, 64 \mathrm{SO}_{2}^{-}, 80 \mathrm{SO}_{3}^{-} \\
81 \mathrm{HSO}_{3}^{-}, 96 \mathrm{SO}_{4}^{-}, 97 \mathrm{HSO}_{4}^{-}\end{array}$ & \\
\hline chloride & & $35 \mathrm{Cl}^{-}, 37 \mathrm{Cl}^{-}$ & $\begin{array}{l}(I 35+I 36): I 37= \\
\sim 3.1(0.5)\end{array}$ \\
\hline elemental carbon & $12_{n} \mathrm{C}_{n}^{+}$ & $12{ }_{n} \mathrm{C}_{n}^{-}$ & \\
\hline organics & & $\begin{array}{l}24 \mathrm{C}_{2}^{-}, 25 \mathrm{C}_{2} \mathrm{H}^{-}, 26 \mathrm{C}_{2} \mathrm{H}_{2} / \mathrm{CN}^{-} \\
26 \mathrm{C}_{2} \mathrm{H}_{2} / \mathrm{CN}^{-}\end{array}$ & \\
\hline \multirow[t]{6}{*}{ organic acids } & & $45 \mathrm{COOH}^{-}, 59 \mathrm{CH}_{2} \mathrm{COOH}^{-}$ & \\
\hline & & $71 \mathrm{CCH}_{2} \mathrm{COOH}^{-}$ & \\
\hline & & $73 \mathrm{C}_{2} \mathrm{H}_{4} \mathrm{COOH}^{-}$ & \\
\hline & & $85 \mathrm{C}_{3} \mathrm{H}_{4} \mathrm{COOH}^{-}$ & \\
\hline & & $99 \mathrm{C}_{4} \mathrm{H}_{6} \mathrm{COOH}^{-}$ & \\
\hline & & $117(\mathrm{CO})_{3} \mathrm{OOH}^{-}$ & \\
\hline nitrogen-containing organics & & $26 \mathrm{CN}^{-}, 42 \mathrm{CNO}^{-}$ & \\
\hline unsaturated organics & & $\begin{array}{l}25 \mathrm{C}_{2} \mathrm{H}^{-}, 26 \mathrm{C}_{2} \mathrm{H}_{2}^{-} \text {, unknown } \\
\text { fragments } 49 \text { - and } 73 \text { - }\end{array}$ & \\
\hline aromatic compounds & $\begin{array}{l}77 \mathrm{C}_{6} \mathrm{H}_{5}^{+}, 91 \mathrm{C}_{7} \mathrm{H}_{7}^{+}, 103 \mathrm{C}_{8} \mathrm{H}_{7}^{+} / \\
105 \mathrm{C}_{8} \mathrm{H}_{0}^{+}, 115 \mathrm{C}_{9} \mathrm{H}_{7}^{+}\end{array}$ & $\begin{array}{l}25 \mathrm{C}_{2} \mathrm{H}^{-}, 26 \mathrm{C}_{2} \mathrm{H}_{2}^{-} \text {, unknown } \\
\text { fragments } 49 \text { - and } 73 \text { - }\end{array}$ & \\
\hline
\end{tabular}

* We have made histograms for each of the three typical peak ratios (ref. Fig. S5). Histogram $x_{0}$ is the expected value that indicates the position of the peak resulting from Gaussian fit, and the width is the corresponding standard deviation. $I$ is short for the intensity of the corresponding peak in LAAPTOF spectra; typical peak ratios for potassium and chloride are based on pure and mixed salt containing $\mathrm{K}$ and $\mathrm{Cl}$; typical peak ratios for silicon are based on pure $\mathrm{SiO}_{2}$.

from Argentina and the USA, reflected in higher intensities at $m / z 24^{-}, 25^{-}$, and $26^{-}$. Argentinian soil dust contains far fewer mineral species, expressed in much lower intensities of mineral signatures, e.g. $\mathrm{m} / z 27^{+}, 28^{+}, 40^{+}, 44^{+}$, and $56^{+}$. The ratios of $m / z 39 \mathrm{~K}^{+}$and $41 \mathrm{~K}^{+}(3.6,3.8,3.5$, and 5.3 for SDGe01, SDPA01, SDAr08, and SDWY01, respectively) are much lower than the typical peak ratio $(\sim 13.5)$ for potassium (Table 2), indicating that they are likely contributed to by both potassium isotopes and hydrocarbon fragments.

For agricultural soil dust particles, obviously ammonium $\left(m / z 18 \mathrm{NH}_{4}^{+}\right.$and $\left.30 \mathrm{NO}^{+}\right)$, phosphate $\left(m / z 63 \mathrm{PO}_{2}^{-}, 79\right.$ $\mathrm{PO}_{3}^{-}$, and $\left.95 \mathrm{PO}_{5}^{-}\right)$, and potassium signatures $\left(\mathrm{m} / z 39 \mathrm{~K}^{+}\right.$ and $41 \mathrm{~K}^{+}$) can be found in the spectra, attributed to fertilization. Apart from that, typical biological signatures were observed: (1) the strong $\mathrm{m} / z 26^{-}, 42^{-}$, and $39^{+}$pattern is similar to the potassium organo-nitrogen particle type observed by an ATOFMS at an urban site in Barcelona (Dall'Osto et al., 2016), which was assigned to carbohydrates arising from biogenic species (Schmidt et al., 2017; Silva et al., 2000). (2) $26^{-}$and $42^{-}$could also be contributed by $\mathrm{CN}^{-}$and $\mathrm{CNO}^{-}$derived from NOCs, i.e. amines, as well as $m / z 30$ $\mathrm{CH}_{3} \mathrm{NH}^{+}, 58 \mathrm{C}_{2} \mathrm{H}_{5} \mathrm{NHCH}_{2}^{+}$, and $59\left(\mathrm{CH}_{3}\right)_{3} \mathrm{~N}^{+}$. These biological signatures have also been observed by ALABAMA in the field (Schmidt et al., 2017). (3) Some weak but reproducibly detected fragment pattern at around $m / z 77 \mathrm{C}_{6} \mathrm{H}_{5}^{+}$, $91 \mathrm{C}_{7} \mathrm{H}_{7}^{+}, 103 \mathrm{C}_{8} \mathrm{H}_{7}^{+}, 105 \mathrm{C}_{8} \mathrm{H}_{9}^{+}$, and $115 \mathrm{C}_{9} \mathrm{H}_{7}^{+}$might originate from aromatic compounds. Similar patterns can also be found for PSL particles.

Other examples for complex mixtures, i.e. illite and sea salt particles with biological components, are provided in the Supplement (Figs. S14 and S11).

All the peak assignments and mass spectral patterns, like signature peaks, as well as some stable peak ratios mentioned above have been summarized in Table S1 in the Supplement and Table 2, respectively. We consider these laboratory-based reference spectra as useful for the analysis of data obtained 
(a)
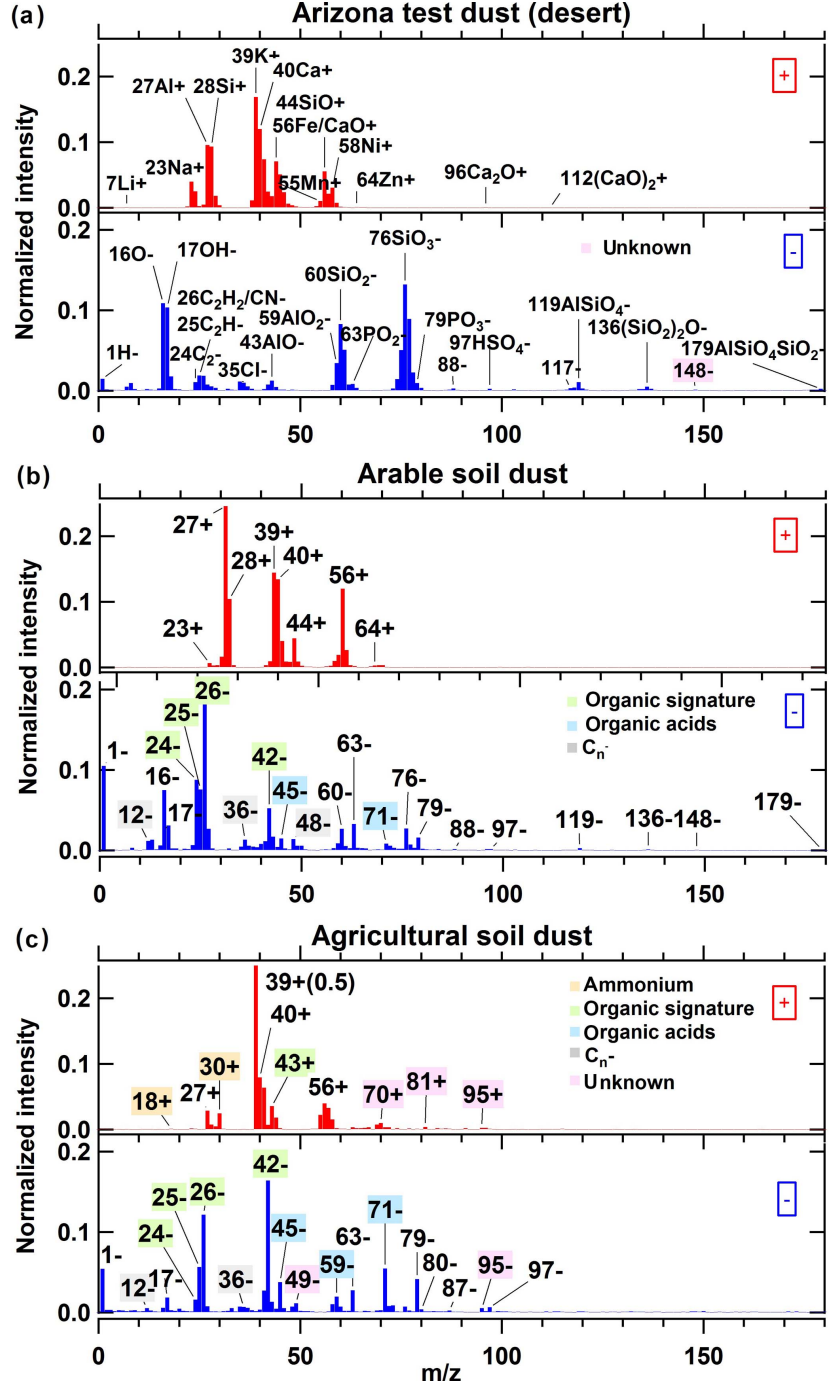

Figure 7. Average mass spectra for particles of complex mixtures: (a) Arizona test dust (desert dust), directly sampled into the LAAPTOF from a shaked bottle (b) arable soil dust, collected from Gottesgabe in Germany, was dispersed by a rotating brush generator and injected via cyclones into the AIDA chamber at $256 \mathrm{~K}$ and $80 \% \mathrm{RH}$, and (c) agricultural soil dust, collected from harvesting machines after rye and wheat harvest, were generated by using the same method as (b). For (b) and (c), fragments labelled in green represent more intensive organic signatures in soil dust particles; grey labels represent EC patterns; blue labels represent organic acids; orange labels represent ammonium salts; red labels represent unknown fragments. The numbers of spectra averaged for each spectrum are 261 (a), 583 (b), and 286 (c).

also by other LAAPTOF versions and to some extent even for other single-particle mass spectrometers. Similar mass spectra are to be expected as long as they use similar ablation and ionization laser pulses $(4 \mathrm{~mJ}, 193 \mathrm{~nm})$, inlet regions for the mass spectrometer, and mass spectrometer types. In the near future, we plan to make these laboratory-based refer- ence spectra publicly available via the EUROCHAMP-2020 database (www.eurochamp.org, last access: 16 April 2018).

\subsection{Interpretation of field data}

Figure 8 shows an example of bipolar mass spectra for six different particle classes measured in the field campaign at a rural site near Leopoldshafen in southwest Germany. On 29 July 2016 within 24 h, 7314 particles were detected and successfully ablated, and mass spectra were generated by LAAPTOF. The 7314 pairs of spectra were then clustered by the fuzzy $c$-means algorithm, resulting in six classes. The resulting number of classes with clearly different features depends on the experience of the operating scientist to identify them (please refer to the details of fuzzy clustering in Procedure 1 in the Supplement). The fuzzy results are compared with the laboratory-based reference spectra by calculating their correlation coefficients (Fig. 9). All classes exhibit a sulfate signature with $m / z 97 \mathrm{HSO}_{4}^{-}$and $m / z 80 \mathrm{SO}_{3}^{-}$; a nitrate signature with $m / z 46 \mathrm{NO}_{2}^{-}$and $62 \mathrm{NO}_{3}^{-}$; an organic compound signature with $m / z 24 \mathrm{C}_{2}^{-}, 25 \mathrm{C}_{2} \mathrm{H}^{-}$, and 26 $\mathrm{C}_{2} \mathrm{H}_{2} / \mathrm{CN}^{-}$; and a NOC signature with $m / z 26 \mathrm{CN}^{-}$and 42 $\mathrm{CNO}^{-}$in the negative spectra. More characteristic signatures for each particle class can be observed in the positive spectra. All particles measured on this day show a $35 \%$ similarity to class 5 with obvious signatures for potassium $(\mathrm{K})$ and sulfate, with significant correlation with the reference particles containing potassium and sulfate (Fig. 9). Additionally, class 5 has a significant correlation with some other cations arising from ammonium, organic compounds, and dust. The ratio of $m / z\left(39^{+}+40^{+}\right)$to $41^{+}$is $\sim 11$, close to the value for pure $\mathrm{K}_{2} \mathrm{SO}_{4}$ particles $(\sim 13.5)$; thus we assigned them to $\mathrm{K}^{+}$rather than organic fragments. Further, there is a $15 \%$ similarity to class 4 with prominent ammonium signatures at $m / z 18 \mathrm{NH}_{4}^{+}$and $30 \mathrm{NO}^{+}$, sulfate signatures, and a relatively weaker but reproducible nitrate signature. The corresponding spectrum is similar to the spectrum for the homogeneous mixtures of $\mathrm{NH}_{4} \mathrm{NO}_{3}$ and $\left(\mathrm{NH}_{4}\right)_{2} \mathrm{SO}_{4}$ (panel a in Fig. 4). This class also has strong correlation with both positive and negative reference spectra for the mixture of ammonium nitrate and ammonium sulfate particles. Ammonium, nitrate, and sulfate are the major secondary inorganic species in atmospheric aerosol particles (Seinfeld and Pandis, 2006); thus we name this class "secondary inorganic". It should be noted that this class has a significant correlation with ammonium and cations arising from oxalic acid; however class 4 has a weak correlation with the signature anion, i.e. $m / z 89 \mathrm{C}_{2} \mathrm{O}_{4} \mathrm{H}^{-}$(oxalate), of oxalic acid. Therefore, we can rule out a significant contribution of oxalic acid. There is also a $15 \%$ similarity to class 2 (sodium rich), with a characteristic pattern of a strong signal at $m / z 23 \mathrm{Na}^{+}$accompanied by two weaker peaks at $m / z 39 \mathrm{~K}^{+}$(with typical potassium peak ratio of $\sim 12$ ) and $63^{+}$(might contain both $\mathrm{Cu}^{+}$and $\mathrm{C}_{5} \mathrm{H}_{3}^{+}$fragments). Class 2 has a significant correlation with the cations (i.e. $\mathrm{Na}$ and $\mathrm{K}$ ) arising from sea salt 

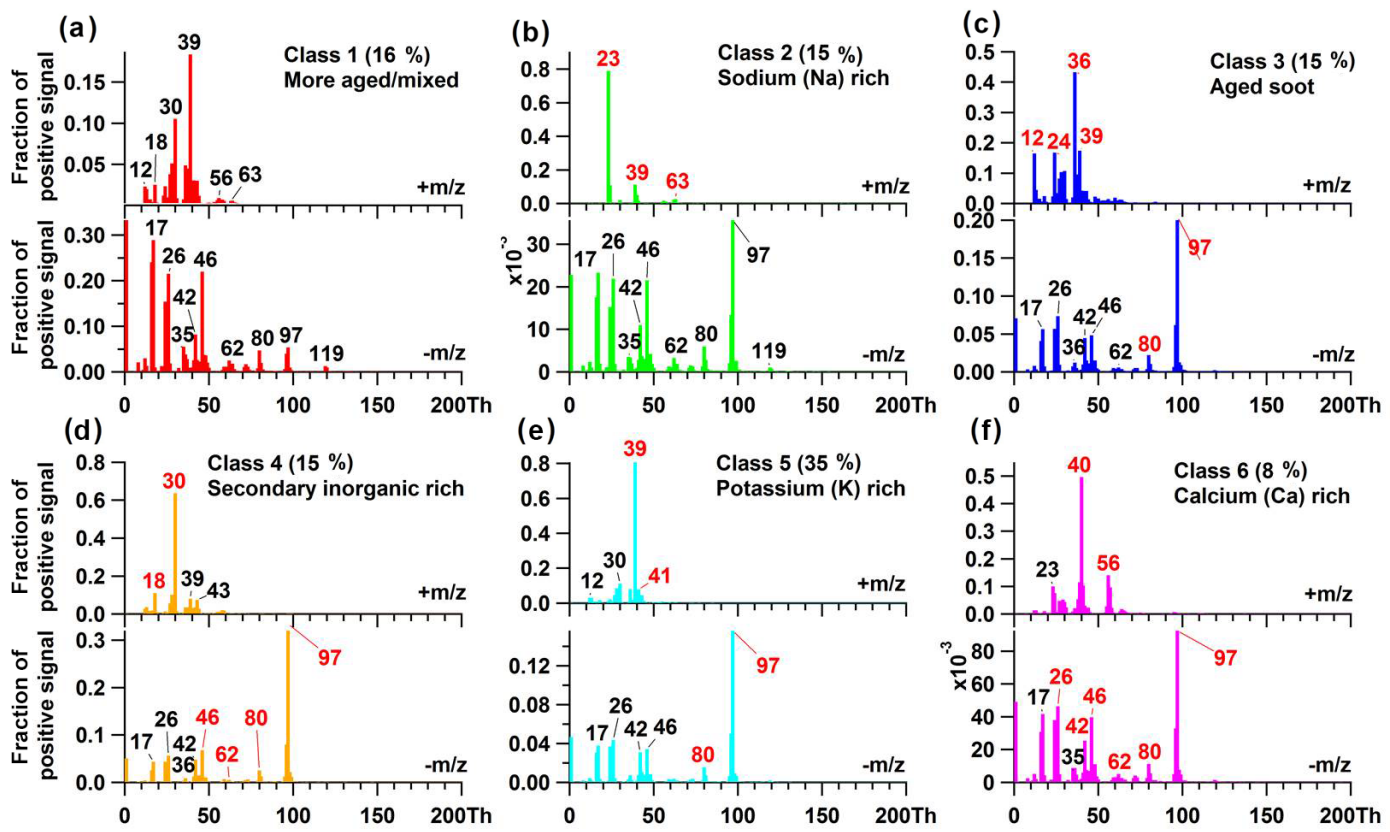

Figure 8. Mass spectra for six classes of particles measured on 29 July 2016 during the field campaign TRAM01, based on classification according to the fuzzy $c$-means algorithm. The percentage in each pair of spectra (a to f) gives us information about the similarity of the total aerosols to different classes. The red tags represent the signatures for each typical class, but there is no red tag in (b), since this class consists of more aged particles containing signatures for different classes. Mean particle size: $d_{\mathrm{va}}(676 \pm 165) \mathrm{nm}$.

but a weak correlation with its anions, such as $m / z 35^{-}$and $37^{-}$chloride isotopes. A sea salt contribution can thus be ruled out. Its negative spectrum significantly correlates with nitrate, sulfate, and dust particles. Besides sodium-rich dust, aged sea salt may be an appropriate classification. Class 3 is named "aged soot", since it has a significant correlation with soot particles, especially diesel soot, and a prominent sulfate signal. This class has an EC pattern with $m / z 12 \mathrm{n} \mathrm{C}_{n}^{+}$, similar to those in the reference spectra for soot particles (Fig. 6) as well as the reference spectra for PSL particles (Fig. S9). The patterns at $m / z 27 \mathrm{C}_{2} \mathrm{H}_{3}^{+}$and $28 \mathrm{CO}^{+} ; m / z 36 \mathrm{C}_{3}^{+}$and 39 $\mathrm{C}_{3} \mathrm{H}_{3}^{+}$; and the $m / z 24^{-}, 25^{-}$, and $26^{-}$with higher $m / z 26^{-}$ indicate an OC contribution. This is supported by the correlations, especially with PSL particles, as well as several other organic compounds, suggesting that this class of particles contains organic species. Class 6 is dominated by calcium $(\mathrm{Ca})$ and sulfate with characteristic calcium signature peaks at $m / z 40 \mathrm{Ca}^{+}$and $56 \mathrm{CaO}^{-}$, also found in the spectra for dust particles (Figs. 7, S12, and S13). $M / z 40^{+}$and $56^{+}$ may also contain $40 \mathrm{C}_{2} \mathrm{O}^{+}$and $56 \mathrm{Fe} / \mathrm{C}_{4} \mathrm{H}_{8}^{+}$fragments, respectively. Class 1 contains almost all fragments observed in other classes and is thus named "more aged/mixed particles". As shown in Fig. 9, class 6 is consequently correlated with almost all of the reference spectra (both positive and negative ones).

In order to further interpret the field data, we also classified the ambient mass spectra only based on correlation with 17 selected laboratory-based reference spectra (10 positive
+7 negative spectra) listed in Table S2. This approach resulted in 13 particle types, 7 more than were distinguished by fuzzy clustering. It should be mentioned that at the beginning we were able to identify all but the Ca-rich particle class resulting from fuzzy clustering, since initially we did not have a reference for this type. We therefore used class 6 as an additional reference spectrum for this type of particles, which is among one of the 13 types (here we use "types" instead of "classes" in order to differentiate these two classification methods). Their corresponding spectra are shown in Fig. 10. All the types above the dashed line (panels a to i) exhibit more prominent secondary inorganic signatures $\left(m / z 97 \mathrm{HSO}_{4}^{-}\right)$and higher number fractions than the ones below the dashed line. Although particle types A to I all exhibit a more prominent sulfate pattern with $\mathrm{m} / z 80$ and 97 than nitrate pattern with $m / z 46$ and 62, they are more highly correlated with the mixture of nitrate and sulfate than either of them. Therefore, we assign the corresponding types to nitrate and sulfate. All the types in the lower panels ( $\mathrm{j}$ to $\mathrm{m}$ ) have significant correlation with arable soil dust in the negative spectra, which have organic signatures (e.g. $\mathrm{m} / \mathrm{z} 24^{-}, 25^{-}$, and $26^{-}$) as well as some mineral signatures like $m / z 119^{-}$. Compared with the negative spectra, the positive spectra are more characteristic, which was also observed in the fuzzy results. Type A, B, C, D, and E are comparable with fuzzy class $5,4,2,6$, and 3 , respectively (the correlation coefficients are 0.89 for type A and class 5, 0.95 for type B and class 4, 0.84 for type $\mathrm{C}$ and class 2, 0.76 for type D and 


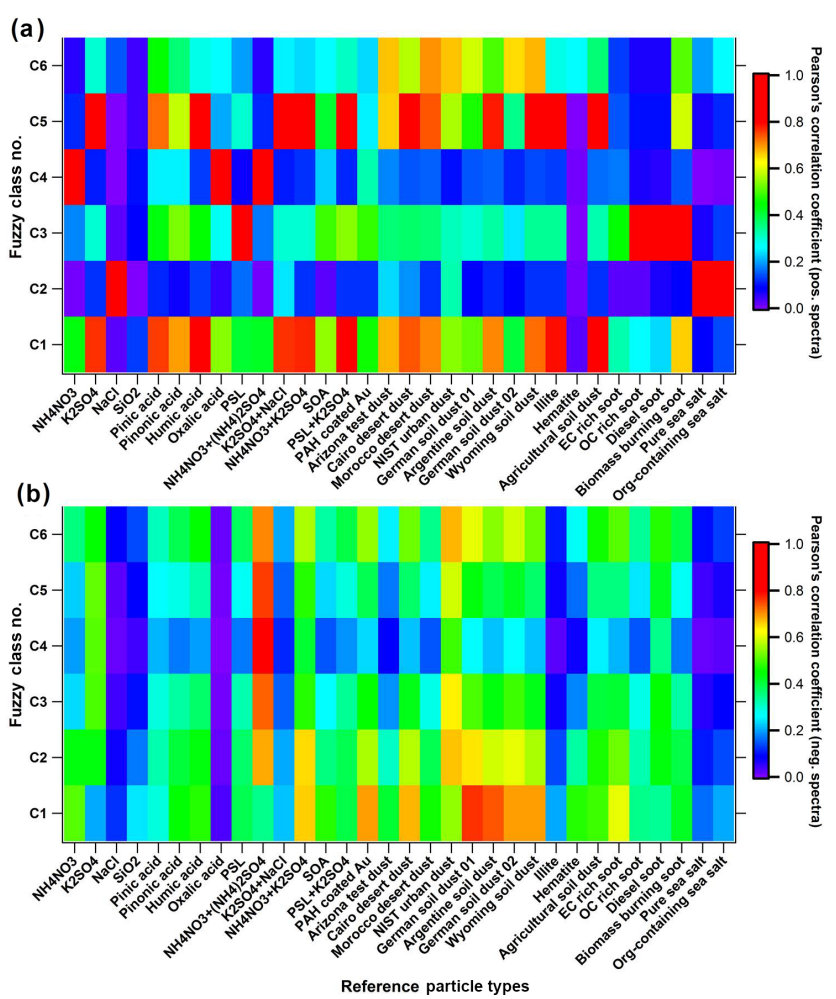

Figure 9. Correlation between fuzzy classification results (6 classes, $\mathrm{C} 1$ to $\mathrm{C} 6$ ) and laboratory-based reference spectra. (a) and (b) are the correlation results for the positive and negative spectra, respectively. PAH is short for poly(allylamine hydrochloride); biomass burning soot is the lignocellulosic char from chestnut wood.

class 6 , and 0.81 for type $\mathrm{E}$ and class 3 ). Types $\mathrm{F}$ to I are more similar to aged/mixed particles, with more fragments than types A to E. Type $\mathrm{H}$ is comparable with fuzzy class 1. About $10 \%$ of the particles cannot be grouped into any type. This is most likely because of an incorrect mass assignment for the stick spectra, resulting from too-large spectrumto-spectrum peak shifts for the same ion fragments/clusters which cannot be corrected on a single-particle basis with the existing software (Ramisetty et al., 2017). As shown in the spectra in both Figs. 8 and 10, all organic species were internally mixed with inorganic species.

This reference-spectra-based classification can also be used for identification of particles with low number fractions among the huge amount of ambient data, and for selection of particles containing particular species, e.g. ones to which the instrument has a lower sensitivity. This can be achieved by e.g. excluding peaks with high signal, such as $m / z 39$ $\mathrm{K} / \mathrm{C}_{3} \mathrm{H}_{3}^{+}$, or by selecting a certain particle size range or mass range. As an example, 55 lead-containing particles $(\mathrm{Pb}$, with isotopes at $m / z 206,207$, and 208) (details are given in the Procedure 3 in the Supplement) were identified among the 7314 ambient aerosol particles. The resulting spectra of particle classes/types in one field study can also be used as a reference for other studies. More applications of these procedures for field data interpretation will be presented in an upcoming paper.

In short, fuzzy and reference-spectra-based classifications have some comparable results with high correlations $(r$ : 0.76-0.95) and also have different advantages: fuzzy classification can identify special ambient particle types without any existing reference if they have a significant abundance and signal strength, while reference-spectra-based methods can identify target particle types even with little abundance. They are complementary to some extent, and thus their combination has the potential to improve interpretation of field data.

\section{Conclusions}

In this study, the overall detection efficiency (ODE) of LAAPTOF was determined to range from $\sim(0.01 \pm 0.01)$ to $\sim(4.23 \pm 2.36) \%$ for polystyrene latex (PSL), with the size of 200 to $2000 \mathrm{~nm}, \sim(0.44 \pm 0.19)$ to $\sim(6.57 \pm 2.38) \%$ for ammonium nitrate $\left(\mathrm{NH}_{4} \mathrm{NO}_{3}\right)$ and $\sim(0.14 \pm 0.02)$ to $\sim(1.46 \pm 0.08) \%$ for sodium chloride $(\mathrm{NaCl})$ particles in the size range of 300 to $1000 \mathrm{~nm}$. This is a relative good detection efficiency compared to earlier versions of the instruments, especially when considering the good reproducibility and stability even during field measurements. A comparison to other single-particle mass spectrometers is the subject of another study and will be discussed in a separate publication. Matrix effects from aerosol particles (e.g. size, morphology, and optical property) and certain instrument influences (e.g. aerodynamic lens, detection system) and their interaction must be taken into account to evaluate the LAAPTOF performance.

In order to facilitate the interpretation of single-particle mass spectra from field measurements, we have measured various well-defined atmospherically relevant aerosol particles in the laboratory and provide here laboratory-based reference spectra for aerosol particles of different complexity with comprehensive spectral information about the components (such as organic compounds, elemental carbon, sulfate, nitrate, ammonium, chloride, mineral compounds, and metals, as commonly observed in atmospheric aerosol particles). Our results show that the interpretation of spectra from unknown particle types is significantly supported by using known mass spectral patterns like signature peaks for ammonium, nitrate, sulfate, and organic compounds as well as typical peak ratios for e.g. potassium, silicon, and chlorides. Spectra for internally mixed particles may show new clusters of ions, rather than simply a combination of the ions from single-component particles. This may be a complication for data interpretation which can be overcome if suitable reference spectra for correspondingly mixed particles are available. Organic compounds generally have some ions in common but exhibit variations depending on the com- 

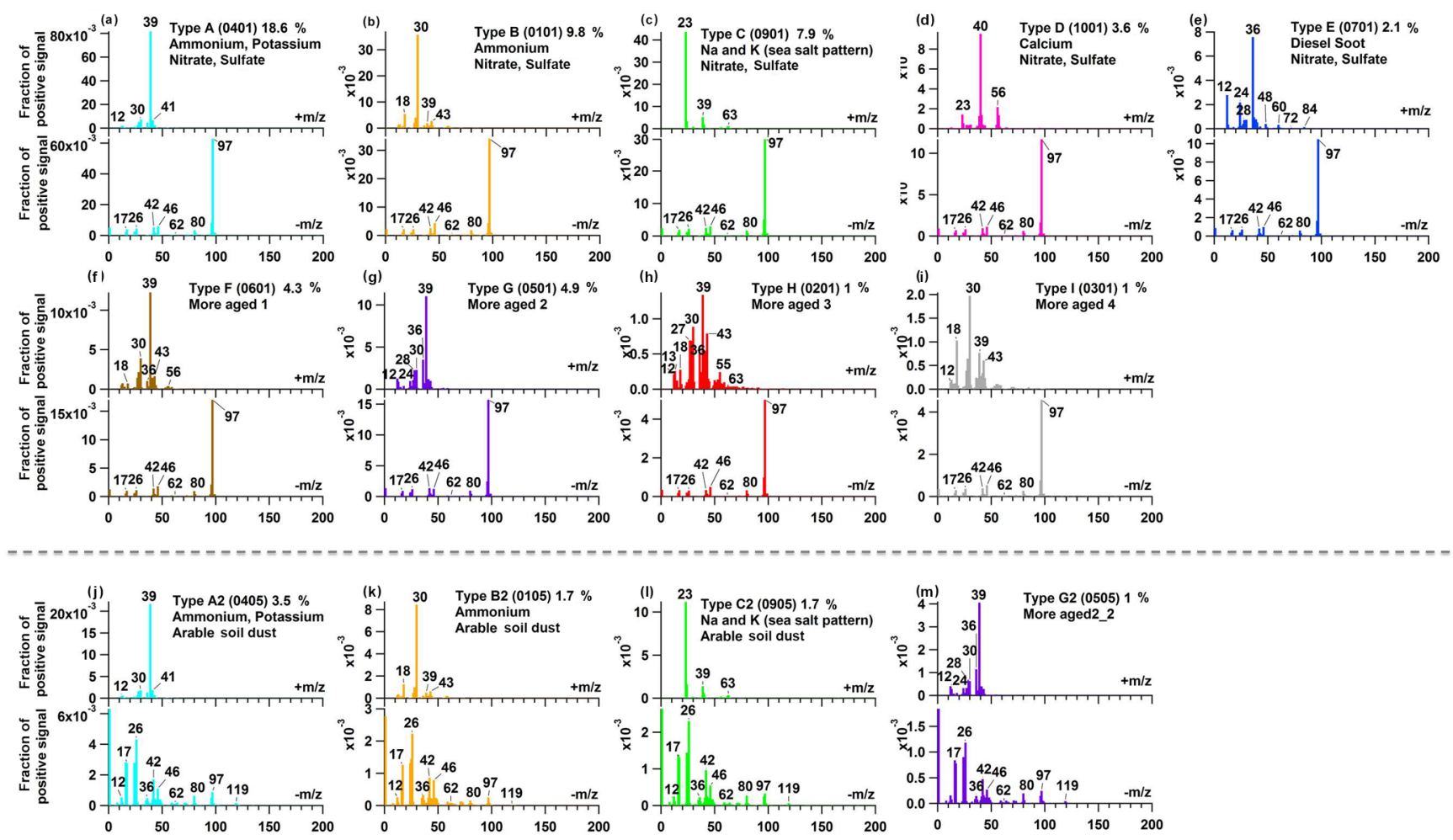

Figure 10. Mass spectra for 13 different types of particles measured on 29 July 2016 during the field campaign TRAM01, based on the classification according to laboratory-based reference spectra. The four-digit codes in the brackets represent particle types (refer to Table S2). The percent values are the particle number fractions. For (a) to (e) and (j) to (l), there are two lines for the names; the first and second lines correspond to the highly correlated positive and negative references, respectively.

pound. Several peaks can originate from different fragments: for example, $m / z 26^{-}$and $42^{-}$could be $\mathrm{CN}^{-}$and $\mathrm{CNO}^{-}$ and/or $\mathrm{C}_{2} \mathrm{H}_{2}^{-}$and $\mathrm{C}_{2} \mathrm{H}_{2} \mathrm{O}^{-}, m / z 39^{+}$and $41^{+}$could originate from $\mathrm{K}^{+}$isotopes and/or organic fragments, and organic matter can also be ionized to form the typical elemental carbon pattern with $\mathrm{C}_{n}^{+/-}$ions. Hence the interpretation is not always unambiguously possible for such particles but may require additional information (e.g. size, additional marker peaks, or even higher-resolution spectra) or comparison to data from other instruments like online aerosol mass spectrometers (e.g. AMS) or chemical ionization mass spectrometers (e.g. FIGAERO-CIMS).

A set of 7314 mass spectra obtained during 1 day of field measurements was used for particle type classification by both fuzzy clustering and reference spectra. Fuzzy clustering yielded six different classes, which could then be identified with the help of reference spectra. Classification of the mass spectra based on comparison with 17 reference spectra resulted in 13 different particle types, 6 of which exhibited high correlation with the fuzzy clusters $(r: 0.76-0.95)$. Compared with the reference spectra, we found that each particle class/type has a sulfate signature at $m / z 80 \mathrm{SO}_{3}^{-}$and 97 $\mathrm{HSO}_{4}^{-}$; a nitrate signature at $m / z 46 \mathrm{NO}_{2}^{-}$and $62 \mathrm{NO}_{3}^{-}$; an organic compound signature at $m / z 24 \mathrm{C}_{2}^{-}, 25 \mathrm{C}_{2} \mathrm{H}^{-}$, and
$26 \mathrm{C}_{2} \mathrm{H}_{2} / \mathrm{CN}^{-}$; and a nitrogen-containing organic signature at $m / z 26 \mathrm{CN}^{-}$and $42 \mathrm{CNO}^{-}$. Furthermore, we performed a target-oriented classification by using selected reference spectra, allowing for the identification of particles with low number fraction in the ambient aerosol, e.g. lead-containing particles. Based on our results, we advise using a combination of both methods for the analysis of SPMS field data.

We conclude that the reference spectra presented in this paper are useful for interpretation of field measurements and for understanding the impact of mixing on typical mass spectral signatures. Furthermore, the reference spectra should be useful for interpretation of data obtained by other LAAPTOF versions or other single-particle mass spectrometers using a similar ionization method and comparable mass spectrometers. For future experiments using the LAAPTOF, systematic studies are still required on its sensitivity to different species, distinguishing the organic and inorganic contribution to the same peak in the spectra, and investigating peak ratios.

Data availability. The reference spectra are available upon request from the authors and are available in electronic format via the EUROCHAMP DATA CENTER - Library of Analytical Resources of the EU project EUROCHAMP-2020 (https://data.eurochamp.org/, EUROCHAMP, 2018). 


\section{The Supplement related to this article is available online at https://doi.org/10.5194/amt-11-2325-2018-supplement.}

Author contributions. XS characterized the LAAPTOF, measured all the particles samples, did the data analysis, produced all figures, and wrote the manuscript. RR helped to characterize the LAAPTOF and to measure some of the particle samples. CM provided technical and scientific support for characterizing the LAAPTOF as well as data analysis, and for interpretation and discussion of the results. WH provided scientific support for interpretation and discussion of the results. TL gave general advices and comments for this paper. HS provided technical and scientific support for characterizing the LAAPTOF, as well as suggestions for the data analysis, interpretation, and discussion. All authors contributed to the final text.

Competing interests. The authors declare that they have no conflict of interest.

Acknowledgements. The authors gratefully thank the AIDA staff at KIT for helpful discussions and technical support, and the China Scholarship Council (CSC) for financial support of Xiaoli Shen and Wei Huang. Special thanks go to Robert Wagner for Mie calculation and discussion and comments on the sea salt samples; to Thea Schiebel, Kristina Höhler, and Ottmar Möhler for discussions about the soil dust samples; to Isabelle Steinke for discussions regarding the plant samples; to Konrad Kandler for providing the Morocco desert dust samples; to Roger Funk and Thomas Hill for providing the soil dust samples; to Elena Gorokhova and Matt Salter for providing the sea salt with Skeletonema marinoi culture; and to AeroMegt $\mathrm{GmbH}$ for discussions about the LAAPTOF performance and analysis software.

The article processing charges for this open-access publication were covered by a Research

Centre of the Helmholtz Association.

Edited by: Joachim Curtius

Reviewed by: two anonymous referees

\section{References}

Ackerman, A. A., Adam, J. A., Cairns, B., Cho, H., Gritsevich, M., Jethva, H., Kacenelenbogen, M., Kandler, K., Knobelspiesse, K., Lanconelli, C., Lupi, A., Mazzola, M., Nousiainen, T., Peltoniemi, J. I., Platnick, S., Puttonen, E., Savenkov, S. N., SegalRosenheimer, M., Sharma, S., Tomasi, C., Torres, O., and Zhang, Z.: Light scattering reviews 9: Light scattering and radiative transfer, Springer-Praxis, 2015

Ahern, A. T., Subramanian, R., Saliba, G., Lipsky, E. M., Donahue, N. M., and Sullivan, R. C.: Effect of secondary organic aerosol coating thickness on the real-time detection and characterization of biomass-burning soot by two particle mass spectrometers, Atmos. Meas. Tech., 9, 6117-6137, https://doi.org/10.5194/amt-96117-2016, 2016.
Arndt, J., Sciare, J., Mallet, M., Roberts, G. C., Marchand, N., Sartelet, K., Sellegri, K., Dulac, F., Healy, R. M., and Wenger, J. C.: Sources and mixing state of summertime background aerosol in the north-western Mediterranean basin, Atmos. Chem. Phys., 17, 6975-7001, https://doi.org/10.5194/acp17-6975-2017, 2017.

Bohren, C. F. and Huffman, R. D.: Absorption and scattering of light by small particles, WILEY-VCH Verlag GmbH \& Co. KGaA, 2007.

Brands, M., Kamphus, M., Böttger, T., Schneider, J., Drewnick, F., Roth, A., Curtius, J., Voigt, C., Borbon, A., Beekmann, M., Bourdon, A., Perrin, T., and Borrmann, S.: Characterization of a newly developed aircraft-based laser ablation aerosol mass spectrometer (ALABAMA) and first field deployment in urban pollution plumes over Paris during MEGAPOLI 2009, Aerosol Sci. Tech., 45, 46-64, 2011.

Burkholder, J. B., Abbatt, J. P. D., Barnes, I., Roberts, J. M., Melamed, M. L., Ammann, M., Bertram, A. K., Cappa, C. D., Carlton, A. G., Carpenter, L. J., Crowley, J. N., Dubowski, Y., George, C., Heard, D. E., Herrmann, H., Keutsch, F. N., Kroll, J. H., McNeill, V. F., Ng, N. L., Nizkorodov, S. A., Orlando, J. J., Percival, C. J., Picquet-Varrault, B., Rudich, Y., Seakins, P. W., Surratt, J. D., Tanimoto, H., Thornton, J. A., Tong, Z., S., T. G., Wahner, A., Weschler, C. J., Wilson, K. R., and Ziemann, P. J.: The essential role for laboratory studies in atmospheric chemistry, Environ. Sci. Technol., 51, 2519-2528, 2017.

Canagaratna, M. R., Jayne, J. T., Jimenez, J. L., Allan, J. D., Alfarra, M. R., Zhang, Q., Onasch, T. B., Drewnick, F., Coe, H., Middlebrook, A., Delia, A., Williams, L. R., Trimborn, A. M., Northway, M. J., DeCarlo, P. F., Kolb, C. E., Davidovits, P., and Worsnop, D. R.: Chemical and microphysical characterization of ambient aerosols with the aerodyne aerosol mass spectrometer, Mass Spectrom. Rev., 26, 185-222, 2007.

Dall'Osto, M., Beddows, D. C. S., McGillicuddy, E. J., Esser-Gietl, J. K., Harrison, R. M., and Wenger, J. C.: On the simultaneous deployment of two single-particle mass spectrometers at an urban background and a roadside site during SAPUSS, Atmos. Chem. Phys., 16, 9693-9710, https://doi.org/10.5194/acp16-9693-2016, 2016.

EUROCHAMP: EUROCHAMP DATA CENTER - Library of Analytical Resources of the EU project EUROCHAMP-2020, available at: https://data.eurochamp.org/, last access: 16 April 2018.

Gaie-Levrel, F., Perrier, S., Perraudin, E., Stoll, C., Grand, N., and Schwell, M.: Development and characterization of a single particle laser ablation mass spectrometer (SPLAM) for organic aerosol studies, Atmos. Meas. Tech., 5, 225-241, https://doi.org/10.5194/amt-5-225-2012, 2012.

Gemayel, R., Hellebust, S., Temime-Roussel, B., Hayeck, N., Van Elteren, J. T., Wortham, H., and Gligorovski, S.: The performance and the characterization of laser ablation aerosol particle time-of-flight mass spectrometry (LAAP-ToF-MS), Atmos. Meas. Tech., 9, 1947-1959, https://doi.org/10.5194/amt-9-19472016, 2016.

Gross, D. S., Gälli, M. E., Silva, P. J., and Prather, K. A.: Relative sensitivity factors for alkali metal and ammonium cations in single particle aerosol time-of-flight mass spectra, Anal. Chem., 72, 416-422, 2000.

Hagemann, R., Corsmeier, U., Kottmeier, C., Rinke, R., Wieser, A., and Vogel, B.: Spatial variability of particle number concentra- 
tions and NOx in the Karlsruhe (Germany) area obtained with the mobile laboratory "AERO-TRAM", Atmos. Environ., 94, 341352, 2014.

Hinz, K. P., Greweling, M., Drews, F., and Spengler, B.: Data processing in on-line laser mass spectrometry of inorganic, organic, or biological airborne particles, J. Am. Soc. Mass Spectr., 10, 648-660, 1999.

Jimenez, J. L., Canagaratna, M. R., Donahue, N. M., Prevot, A. S. H., Zhang, Q., Kroll, J. H., DeCarlo, P. F., Allan, J. D., Coe, H., Ng, N. L., Aiken, A. C., Docherty, K. S., Ulbrich, I. M., Grieshop, A. P., Robinson, A. L., Duplissy, J., Smith, J. D., Wilson, K. R., Lanz, V. A., Hueglin, C., Sun, Y. L., Tian, J., Laaksonen, A., Raatikainen, T., Rautiainen, J., Vaattovaara, P., Ehn, M., Kulmala, M., Tomlinson, J. M., Collins, D. R., Cubison, M. J., Dunlea, E. J., Huffman, J. A., Onasch, T. B., Alfarra, M. R., Williams, P. I., Bower, K., Kondo, Y., Schneider, J., Drewnick, F., Borrmann, S., Weimer, S., Demerjian, K., Salcedo, D., Cottrell, L., Griffin, R., Takami, A., Miyoshi, T., Hatakeyama, S., Shimono, A., Sun, J. Y., Zhang, Y. M., Dzepina, K., Kimmel, J. R., Sueper, D., Jayne, J. T., Herndon, S. C., Trimborn, A. M., Williams, L. R., Wood, E. C., Middlebrook, A. M., Kolb, C. E., Baltensperger, U., and Worsnop, D. R.: Evolution of organic aerosols in the atmosphere, Science, 326, 1525-1529, 2009.

Johnston, M. V.: Sampling and analysis of individual particles by aerosol mass spectrometry, J. Mass Spectrom., 35, 585-595, 2000.

Kamphus, M., Ettner-Mahl, M., Brands, M., Curtius, J., Drewnick, F., and Borrmann, S.: Comparison of two aerodynamic lenses as an inlet for a single particle laser ablation mass spectrometer, Aerosol Sci. Tech., 42, 970-980, 2008.

Kulkarni, P., Baron, P. A., and Willeke, K.: Aerosol measurement: Principles,techniques, and applications, Wiley, J \& Sons, Inc., 2011.

Li, L., Huang, Z. X., Dong, J. G., Li, M., Gao, W., Nian, H. Q., Fu, Z., Zhang, G. H., Bi, X. H., Cheng, P., and Zhou, Z.: Real time bipolar time-of-flight mass spectrometer for analyzing single aerosol particles, Int. J. Mass Spectrom., 303, 118-124, 2011.

Li, W., Sun, J., Xu, 1., Shi, Z., Riemer, N., Sun, Y., Fu, P., Zhang, J., Lin, Y., Wang, X., Shao, L., Chen, J., Zhang, X., Wang, Z., and Wang, W.: A conceptual framework for mixing structures in individual aerosol particles, J. Geophys. Res.-Atmos., 121, 1378413798, 2016.

Lin, Q., Zhang, G., Peng, L., Bi, X., Wang, X., Brechtel, F. J., Li, M., Chen, D., Peng, P., Sheng, G., and Zhou, Z.: In situ chemical composition measurement of individual cloud residue particles at a mountain site, southern China, Atmos. Chem. Phys., 17, 84738488, https://doi.org/10.5194/acp-17-8473-2017, 2017.

Liu, P., Ziemann, P. J., Kittelson, D. B., and McMurry, P. H.: Generating particle beams of controlled dimensions and divergence: II. Experimental evaluation of particle motion in aerodynamic lenses and nozzle expansions, Aerosol Sci. Tech., 22, 314-324, 1995.

Marsden, N., Flynn, M. J., Taylor, J. W., Allan, J. D., and Coe, H.: Evaluating the influence of laser wavelength and detection stage geometry on optical detection efficiency in a singleparticle mass spectrometer, Atmos. Meas. Tech., 9, 6051-6068, https://doi.org/10.5194/amt-9-6051-2016, 2016.

Marsden, N. A., Flynn, M. J., Allan, J. D., and Coe, H.: Online differentiation of mineral phase in aerosol particles by ion formation mechanism using a LAAP-TOF singleparticle mass spectrometer, Atmos. Meas. Tech., 11, 195-213, https://doi.org/10.5194/amt-11-195-2018, 2018.

Moffet, R. C., de Foy, B., Molina, L. T., Molina, M. J., and Prather, K. A.: Measurement of ambient aerosols in northern Mexico City by single particle mass spectrometry, Atmos. Chem. Phys., 8, 4499-4516, https://doi.org/10.5194/acp-8-4499-2008, 2008.

Murphy, D. M.: The design of single particle laser mass spectrometers, Mass Spectrom. Rev., 26, 150-165, 2007.

Murphy, D. M., Middlebrook, A. M., and Warshawsky, M.: Cluster analysis of data from the Particle Analysis by Laser Mass Spectrometry (PALMS) instrument, Aerosol Sci. Tech., 37, 382-391, 2003.

Murphy, D. M., Cziczo, D. J., Froyd, K. D., Hudson, P. K., Matthew, B. M., Middlebrook, A. M., Peltier, R. E., Sullivan, A., Thomson, D. S., and Weber, R. J.: Single-particle mass spectrometry of tropospheric aerosol particles, J. Geophys. Res.-Atmos., 111, D23S32, https://doi.org/10.1029/2006JD007340, 2006.

Noble, C. A. and Prather, K. A.: Real-time single particle mass spectrometry: a historical review of a quarter century of the chemical analysis of aerosols, Mass Spectrom. Rev., 19, 248274, 2000.

Pöschl, U.: Atmospheric aerosols: Composition, transformation, climate and health effects, Angew. Chem. Int. Edit., 44, 7520 7540, 2005.

Pratt, K. A. and Prather, K. A.: Mass spectrometry of atmospheric aerosols-Recent developments and applications. Part II: On-line mass spectrometry techniques, Mass Spectrom. Rev., 31, 17-48, 2012.

Ramisetty, R., Abdelmonem, A., Shen, X., Saathoff, H., Leisner, T., and Mohr, C.: Exploring femtosecond laser ablation in single particle aerosol mass spectrometry, Atmos. Meas. Tech. Discuss., https://doi.org/10.5194/amt-2017-357, in review, 2017.

Reitz, P., Zorn, S. R., Trimborn, S. H., and Trimborn, A. M.: A new, powerful technique to analyze single particle aerosol mass spectra using a combination of OPTICS and the fuzzy c-means algorithm, J. Aerosol Sci., 98, 1-14, 2016.

Roth, A., Schneider, J., Klimach, T., Mertes, S., van Pinxteren, D., Herrmann, H., and Borrmann, S.: Aerosol properties, source identification, and cloud processing in orographic clouds measured by single particle mass spectrometry on a central European mountain site during HCCT-2010, Atmos. Chem. Phys., 16, 505524, https://doi.org/10.5194/acp-16-505-2016, 2016.

Saathoff, H., Möhler, O., Schurath, U., Kamm, S., Dippel, B., and Mihelcic, D.: The AIDA soot aerosol characterisation campaign 1999, J. Aerosol Sci., 34, 1277-1296, 2003.

Saathoff, H., Naumann, K.-H., Möhler, O., Jonsson, Å. M., Hallquist, M., Kiendler-Scharr, A., Mentel, Th. F., Tillmann, R., and Schurath, U.: Temperature dependence of yields of secondary organic aerosols from the ozonolysis of $\alpha$-pinene and limonene, Atmos. Chem. Phys., 9, 1551-1577, https://doi.org/10.5194/acp9-1551-2009, 2009.

Schill, G. P. and Tolbert, M. A.: Heterogeneous ice nucleation on phase-separated organic-sulfate particles: effect of liquid vs. glassy coatings, Atmos. Chem. Phys., 13, 4681-4695, https://doi.org/10.5194/acp-13-4681-2013, 2013.

Schmidt, S., Schneider, J., Klimach, T., Mertes, S., Schenk, L. P., Kupiszewski, P., Curtius, J., and Borrmann, S.: Online single particle analysis of ice particle residuals from mountain-top mixed- 
phase clouds using laboratory derived particle type assignment, Atmos. Chem. Phys., 17, 575-594, https://doi.org/10.5194/acp17-575-2017, 2017.

Schreiner, J., Schild, U., Voigt, C., and Mauersberger, K.: Focusing of aerosols into a particle beam at pressures from 10 to 150 Torr, Aerosol Sci. Tech., 31, 373-382, 1999.

Seinfeld, J. H. and Pandis, S. N.: Atmospheric chemistry and physics: From air pollution to climate change, Wiley, J \& Sons, Inc., Hoboken, New Jersey, 2006.

Silva, P. J., Carlin, R. A., and Prather, K. A.: Single particle analysis of suspended soil dust from Southern California, Atmos. Environ., 34, 1811-1820, 2000.

Su, Y. X., Sipin, M. F., Furutani, H., and Prather, K. A.: Development and characterization of an aerosol time-of-flight mass spectrometer with increased detection efficiency, Anal. Chem., 76, 712-719, 2004.

Tsigaridis, K., Krol, M., Dentener, F. J., Balkanski, Y., Lathière, J., Metzger, S., Hauglustaine, D. A., and Kanakidou, M.: Change in global aerosol composition since preindustrial times, Atmos. Chem. Phys., 6, 5143-5162, https://doi.org/10.5194/acp-6-51432006, 2006.

Usher, C. R., Michel, A. E., and Grassian, V. H.: Reactions on mineral dust, Chem. Rev., 103, 4883-4939, 2003.

Wagner, R., Kaufmann, J., Möhler, O., Saathoff, H., Schnaiter, M., Ullrich, R., and Leisner, T.: Heterogeneous ice nucleation ability of $\mathrm{NaCl}$ and sea salt aerosol particles at cirrus temperatures, J. Geophys. Res., 123, 2841-2860, https://doi.org/10.1002/2017JD027864, 2018.

Williams, L. R., Gonzalez, L. A., Peck, J., Trimborn, D., McInnis, J., Farrar, M. R., Moore, K. D., Jayne, J. T., Robinson, W. A., Lewis, D. K., Onasch, T. B., Canagaratna, M. R., Trimborn, A., Timko, M. T., Magoon, G., Deng, R., Tang, D., de la Rosa Blanco, E., Prévôt, A. S. H., Smith, K. A., and Worsnop, D. R.: Characterization of an aerodynamic lens for transmitting particles greater than 1 micrometer in diameter into the Aerodyne aerosol mass spectrometer, Atmos. Meas. Tech., 6, 3271-3280, https://doi.org/10.5194/amt-6-3271-2013, 2013.

Wonaschuetz, A., Kallinger, P., Szymanski, W., and Hitzenberger, R.: Chemical composition of radiolytically formed particles using single-particle mass spectrometry, J. Aerosol Sci., 113, 242249, 2017

Yu, J. Z., Cocker, D. R., Griffin, R. J., Flagan, R. C., and Seinfeld, J. H.: Gas-phase ozone oxidation of monoterpenes: Gaseous and particulate products, J. Atmos. Chem., 34, 207-258, 1999.
Zawadowicz, M. A., Abdelmonem, A., Mohr, C., Saathoff, H., Froyd, K. D., Murphy, D. M., LeisnerI, T., and Cziczo, D. J.: Single-particle time-of-flight mass spectrometry utilizing a femtosecond desorption and ionization laser, Anal. Chem., 87, 12221-12229, 2015.

Zawadowicz, M. A., Lance, S., Jayne, J. T., Croteau, P., Worsnop, D. R., Mahrt, F., Leisner, T., and Cziczo, D. J.: Quantifying and improving the performance of the Laser Ablation Aerosol Particle Time of Flight Mass Spectrometer (LAAPToF) instrument, Atmos. Meas. Tech. Discuss., https://doi.org/10.5194/amt-2017$1,2017$.

Zelenyuk, A. and Imre, D.: Single particle laser ablation time-offlight mass spectrometer: An introduction to SPLAT, Aerosol Sci. Tech., 39, 554-568, 2005.

Zelenyuk, A., Cai, Y., and Imre, D.: From agglomerates of spheres to irregularly shaped particles: Determination of dynamic shape factors from measurements of mobility and vacuum aerodynamic diameters, Aerosol Sci. Tech., 40, 197-217, 2006 a.

Zelenyuk, A., Imre, D., Cai, Y., Mueller, K., Han, Y. P., and Imrich, P.: SpectraMiner, an interactive data mining and visualization software for single particle mass spectroscopy: A laboratory test case, Int. J. Mass Spectrom., 258, 58-73, 2006b.

Zelenyuk, A., Yang, J., Choi, E., and Imre, D.: SPLAT II: An aircraft compatible, ultra-sensitive, high precision instrument for in-situ characterization of the size and composition of fine and ultrafine particles, Aerosol Sci. Tech., 43, 411-424, 2009.

Zhang, Q., Jimenez, J. L., Canagaratna, M. R., Allan, J. D., Coe, H., Ulbrich, I., Alfarra, M. R., Takami, A., Middlebrook, A. M., Sun, Y. L., Dzepina, K., Dunlea, E., Docherty, K., DeCarlo, P. F., Salcedo, D., Onasch, T., Jayne, J. T., Miyoshi, T., Shimono, A., Hatakeyama, S., Takegawa, N., Kondo, Y., Schneider, J., Drewnick, F., Borrmann, S., Weimer, S., Demerjian, K., Williams, P., Bower, K., Bahreini, R., Cottrell, L., Griffin, R. J., Rautiainen, J., Sun, J. Y., Zhang, Y. M., and Worsnop, D. R.: Ubiquity and dominance of oxygenated species in organic aerosols in anthropogenically-influenced Northern Hemisphere midlatitudes, Geophys. Res. Lett., 34, L13801, https://doi.org/10.1029/2007GL029979, 2007.

Zhao, W. X., Hopke, P. K., and Prather, K. A.: Comparison of two cluster analysis methods using single particle mass spectra, Atmos. Environ., 42, 881-892, 2008. 